\title{
Modeling and Validation of Irradiation Damage in Ni-based Alloys for Long- Term LWR Applications
}

Stephanie A. Pitts

September 2017

The INL is a U.S. Department of Energy National Laboratory operated by Battelle Energy Alliance 
INL/EXT-17-43408

\section{Modeling and Validation of Irradiation Damage in Ni- based Alloys for Long-Term LWR Applications}

Stephanie A. Pitts

September 2017

Idaho National Laboratory

Idaho Falls, Idaho 83415

http://www.inl.gov

Prepared for the

U.S. Department of Energy

Office of Nuclear Energy

Under DOE Idaho Operations Office

Contract DE-AC07-05ID14517 
Project Title: Modeling and Validation of Irradiation Damage in Ni-based Alloys for LongTerm LWR Applications

Reporting Frequency:

Recipient:

Award number

Awarding Agency:

Working Partners:

Principal Investigator:

Collaborators:

Other Contributors:
Annual Report 2017

Oregon State University

CFA-15-8489

U.S. DOE, NEUP

Oregon State University

University of Michigan - Ann Arbor

Idaho National Laboratory

University of Manchester

Julie Tucker, School of Mechanical, Industrial and Manufacturing Engineering, Oregon State University

Title: Assistant Professor

Phone: 737-541-5840

Email: Julie.Tucker@oregonstate.edu

Emmanuelle Marquis, University of Michigan - Ann Arbor

Benjamin Spencer, Idaho National Laboratory

Grace Burke, University of Manchester

Fei Teng, Oregon State University

Li-Jen Yu, University of Michigan - Ann Arbor

Stephanie Pitts, Idaho National Laboratory

Octav Ciuca, University of Manchester 


\section{Table of Contents}

$1 \quad$ Project Abstract

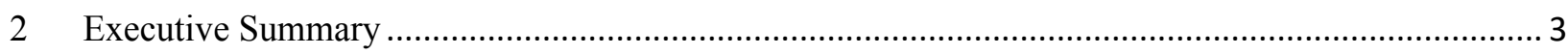

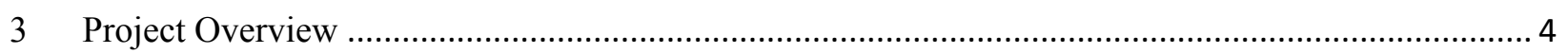

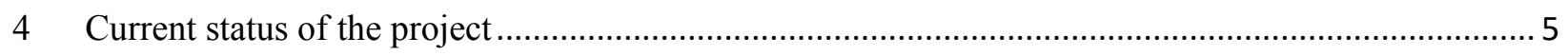

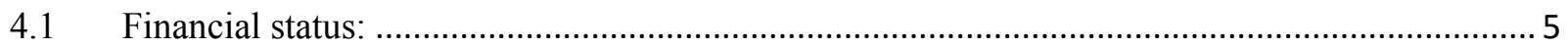

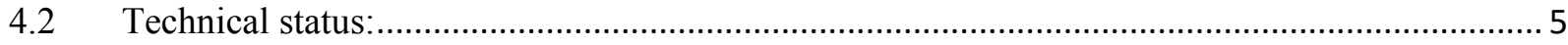

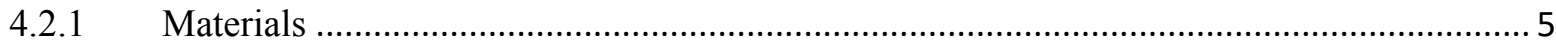

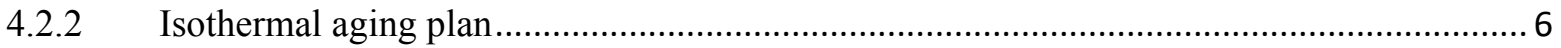

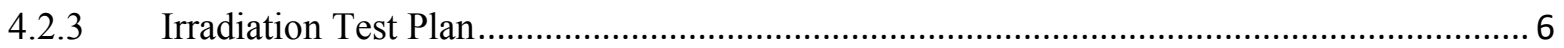

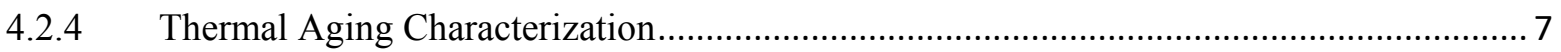

4.2.5 Characterization of Irradiated alloys........................................................................ 19

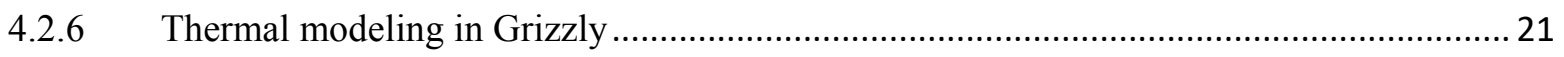

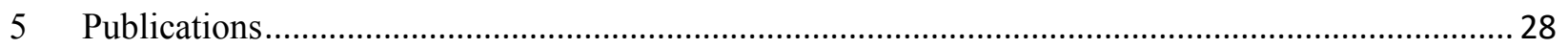

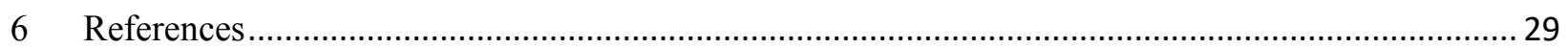

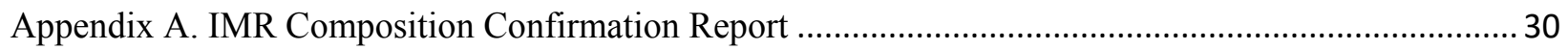


As light water reactor (LWR) plant lives are extended, the need for predictive modeling tools for materials degradation increase in order to ensure safe operation and plan for component replacements. The Grizzly code, which is built on the MOOSE multi-physics simulation environment, is being developed for exactly this purpose. To extend Grizzly to include capabilities for modeling Ni-based alloys, we propose a US/UK integrated program to address thermal and irradiation-induced transformations mechanisms of Alloys 690 and 625. Alloy 690 is widely used in existing LWR plants due to its superior stress corrosion cracking (SCC) resistance compared to Alloy 600. Alloy 625 is used in more limited applications but offers the benefits of both high strength (in the aged condition) and corrosion/SCC resistance [1]. Research has shown that both alloys can undergo phase changes due to thermal or irradiation exposure. In the precipitationhardened condition, Alloy 625 "softens" during neutron irradiation as the strengthening precipitates decompose and metastable precipitates form [2,3]. However, the nature and rates of these transformations as a function of exposure conditions are not well understood. Similarly, the effects of these thermal and irradiation-induced microstructural changes on mechanical properties require evaluation. The proposed program combines thermal and irradiation experiments, mechanical testing, microstructural characterization using state-of-the art analytical techniques, atomistic modeling, micro-and macro-scale modeling via Grizzly. This multi-pronged approach yields several benefits: 1) atomistic scale models capture the physics of the mechanisms of phase transformations, which can be generalized to other systems, 2) the modeling results (from atomistic to continuum) will be validated experimentally to ensure the predictive aspect, 3) the microstructure/property relationships captured with mechanical testing provides information at the engineering scale that is needed to validate the integration of the proposed new capability into Grizzly. 


\section{EXeCUTIVE Summary}

This report summarizes the progress made in the second year of the DOE NEUP project titled "Modeling and Validation of Irradiation Damage in Ni-based Alloys for Long-Term LWR Applications". Year 2 goals were focused on irradiation of model and commercial alloys, characterization of both irradiated and aged materials, and model development. There has been substantial progress in all of these areas.

Key findings presented in this report:

- Microhardness result shows that stoichiometric $\mathrm{Ni} / \mathrm{Cr}=2.0$ samples have higher amounts of hardening than off-stoichiometry samples at all temperatures. However, the rate of total hardness change seems similar regardless of stoichiometry. This has strong implications that off-stoichiometric commercial alloys $\mathrm{Ni} / \mathrm{Cr}=1.8$ to 2.4 will still order at a comparable rates.

- Preliminary irradiation results of model and commercial alloys suggest that protons enhance the ordering phase transformations while ion irradiations do not. This finding will direct future irradiations to alter the dose rate, temperature or irradiating particle in order to balance ballistic mixing with point defect production/diffusion.

- Micropillar compression scoping tests found that in the aged sample, only a few slip planes are active in an angle of $45^{\circ}$, while there are multiple slip parallel planes are active in a smaller angle in unaged sample. Considering the whole pillar was fabricated in a grain with [001] orientation, the active planes' orientation can be identified as [110], which is same as the orientation of ordered structure in $\mathrm{Ni}-\mathrm{Cr}$ system (planes of $\mathrm{Ni}$ and $\mathrm{Cr}$ align along the [110] direction). These preliminary results are interesting and more testing will be pursued in the future to clarify the correlation between the growth of ordering and orientation of active slip planes. 


\section{Project OVERVIEW}

This project combines thermal and irradiation experiments, mechanical testing, microstructural characterization using state-of-the art analytical techniques, atomistic modeling, micro-and macroscale modeling via Grizzly. This multi-pronged approach yields several benefits: 1) atomistic scale models capture the physics of the mechanisms of phase transformations, which can be generalized to other systems, 2) the modeling results (from atomistic to continuum) will be validated experimentally to ensure the predictive aspect, 3) the microstructure/property relationships captured with mechanical testing provides information at the engineering scale that is needed to validate the integration of the proposed new capability into Grizzly. This project has three major objectives:

1. Thermal and irradiation-induced ordering in Alloy 690 and model alloys

2. Thermal and irradiation-induced damage/phase transformations in Alloy 625

3. Development of physics-based predictive models for degradation in Alloys 690/625

Table 1 provides an overview of the major and minor milestones timeline for the project. Year 1 is focused on procuring/fabricating alloys, thermal aging, characterization and irradiations.

Table 1. Detailed major and minor milestone schedule

\begin{tabular}{|l|l|l|l|l|l|l|l|l|l|l|l|l|}
\hline \multicolumn{1}{|c|}{ Major Milestones (All) } & \multicolumn{7}{c|}{ Year 1 } \\
\hline
\end{tabular}




\section{CURRENT STATUS OF THE PROJECT}

\subsection{FinANCIAL STATUS:}

The financial status of the project is currently under budget. There were some delays in spending in year one due to the administration of the subcontract and hiring of students and post docs to support the project. At the end of FY2 Q3 the report show the budget is underspent by $\$ 144 \mathrm{~K}$. These delays in spending will be made up in years three. All funds will still be spent on categories indicated by the initial budget. A no cost extension will be requested if needed to complete the tasks of the project.

The University of Michigan subcontract have been placed for year three. There are currently two full time Ph.D. students working on the projects (Fei Teng and Jen-Li Yu) at Oregon State and University of Michigan. Michigan also just hired a post-doc (Iman Ghamarian) to also help support the project. The University of Manchester also has a post-doc supporting this project (Octav Ciuca), who is funded by the UK government.

\subsection{TECHNICAL STATUS:}

\subsubsection{Materials}

The materials in this study include both model and commercial alloys. Table 2 provides a complete list of materials under investigation. Alloy 690 samples are from Special Metals Heat NX7075HK11. Alloy 625 and 625+ samples are from Carpenter, heats 602051 and 215846, respectively. The commercial alloy chemistries are based on vender certs and most alloying compositions were identified by x-ray fluorescence (XRF). The four binary Ni-Cr model alloys have different Ni:Cr stoichiometries (1.8, 2.0, 2.2 and 2.4). Their compositions have been confirmed by IMR Test Lab (see Appendix A). Test method comes from CAP-017N (ICP-AES) and ASTM E 1019-11 (Comb./IGF). The ternary Ni-Cr-Fe alloys compositions listed were recently manufactured and target compositions are yet to be verified by independent test laboratory.

Table 2. Alloy compositions (wt.\%) for thermal aging studies.

\begin{tabular}{|c|c|c|c|c|c|c|c|c|c|c|}
\hline Alloy & Ni & Cr & Fe & Mo & Nb & Co & Mn & P & S & others \\
\hline 690 & 59.37 & 29.42 & 10.36 & 0.01 & $<0.01$ & 0.009 & 0.15 & 0.004 & $<0.001$ & $*$ \\
\hline 625 & 58.0 & $20.0-$ & 5.0 & $8.0-$ & $3.15-$ & 1.0 & 0.50 & 0.015 & 0.015 & $* *$ \\
& $\min$ & 23.0 & $\max$ & 10.0 & 4.15 & $\max$ & $\max$ & $\max$ & $\max$ & \\
\hline $625+$ & 60.28 & 20.99 & NR & 8.02 & 3.40 & NR & 0.02 & 0.001 & 0.0005 & + \\
\hline Ni:Cr 1.8 & 67.03 & 32.95 & $<0.01$ & - & - & - & - & 0.007 & 0.002 & - \\
\hline Ni:Cr 2.0 & 69.36 & 30.62 & $<0.01$ & - & - & - & - & 0.006 & 0.002 & - \\
\hline Ni:Cr 2.2 & 71.40 & 28.58 & $<0.01$ & - & - & - & - & 0.006 & 0.002 & - \\
\hline Ni:Cr 2.4 & 72.58 & 27.36 & 0.04 & - & - & - & - & 0.006 & 0.001 & - \\
\hline Ni31Cr5Fe & 64 & 31 & 5 & - & - & - & - & - & - & - \\
\hline Ni31Cr7Fe & 62 & 31 & 7 & - & - & - & - & - & - & - \\
\hline Ni31Cr10Fe & 59 & 31 & 10 & - & - & - & - & - & - & - \\
\hline
\end{tabular}

$* \mathrm{C}=0.030, \mathrm{Cu}=0.01, \mathrm{Si}=0.05, \mathrm{Al}=0.27, \mathrm{Ti}=0.28, \mathrm{Mg}=0.001, \mathrm{~B}<0.001, \mathrm{Ca}<0.001, \mathrm{O}=0.01$

** $\mathrm{C}=0.10 \max . \mathrm{Al}=0.4 \max . \mathrm{Ti}=0.4 \max . \mathrm{Si}=0.50 \max . \quad+\mathrm{Al}=0.20 \quad \mathrm{NR}=$ Not reported 


\subsubsection{Isothermal aging plan}

In this project, model alloy samples were given isothermal heat treatments at three temperatures as shown in Table 3. The heat treatment for model alloys is complete. Table 4 shows the test matrix for commercial alloys. This project only includes isothermal aging out to 10,000 hours, however, longer agings are planned. The numbers in test matrices indicate the number of samples for each alloy at that test condition.

Table 3. Test matrix of isothermal aging for model alloys $\mathrm{Ni} / \mathrm{Cr}=1.8-2.4$

\begin{tabular}{|cccccc|}
\hline Time(h) & 500 & 1000 & 3000 & 5000 & 10000 \\
\hline Temp $\left({ }^{\circ} \mathbf{C}\right)$ & & 1 & 1 & 1 & 2 \\
\hline $\mathbf{4 7 5}$ & 1 & 1 & 1 & 1 & 2 \\
\hline $\mathbf{4 1 8}$ & 1 & 1 & 1 & 1 & 2 \\
\hline $\mathbf{3 7 3}$ & 1 & 1 & \\
\hline
\end{tabular}

Table 4. Test matrix of isothermal aging for commercial alloys 690,625 and $625+$

\begin{tabular}{|ccc|}
\hline Time $(h)$ & 10,000 & $20,000+$ \\
\hline $\mathbf{T 7 5}$ & 2 & 6 \\
\hline $\mathbf{4 1 8}$ & 2 & 6 \\
\hline $\mathbf{3 6 0}$ & 2 & 6 \\
\hline $\mathbf{3 3 0}$ & 2 & 6 \\
\hline
\end{tabular}

\subsubsection{Irradiation Test Plan}

Ion and proton irradiation of model and commercial alloys are currently underway at the University of Michigan. To date the following alloys have been irradiated under the conditions listed in Table 5. Future irradiations will be planned based on the characterization results of these initial irradiations.

Table 5. Irradiation conditions completed

\begin{tabular}{|c|c|c|c|c|}
\hline Particle & $\begin{array}{c}\text { Temperature } \\
\left({ }^{\circ} \mathrm{C}\right)\end{array}$ & $\begin{array}{c}\text { Dose rate } \\
(\mathrm{dpa} / \mathrm{s})\end{array}$ & $\begin{array}{c}\text { Dose } \\
(\mathrm{dpa})\end{array}$ & Alloys \\
\hline ion & 300 & $10^{-3}$ & 1.5 & $625,625+, 690, \mathrm{NiCr} 2.0$ \\
\hline ion & 300 & $10^{-4}$ & 1.5 & 625, aged $625,625+$, aged $625+, 690$ \\
\hline proton & 300 & $10^{-5}$ & 1.5 & $625,625+, 690, \mathrm{NiCr} 2.0, \mathrm{NiCr} 2.2, \mathrm{NiCr} 2.4$ \\
\hline proton & 300 & $10^{-5}$ & 6 & $625,625+, 690, \mathrm{NiCr} 1.8, \mathrm{NiCr} 2.0, \mathrm{NiCr} 2.2$ \\
\hline
\end{tabular}




\subsubsection{Thermal Aging Characterization}

\subsubsection{Model alloys}

\section{Microhardness Testing}

The average hardening rates of 10,000 hours as function of stoichiometry at three temperatures are shown in Figure 1. Microhardness result shows that stoichiometry samples have higher amounts of hardening than off-stoichiometry samples at all temperatures. However, the rate of total hardness change seems similar regardless of stoichiometry.

The microhardness of model alloys as a function of ageing time at three temperatures up to 10,000 hours isothermal ageing at 373,418 , and $475^{\circ} \mathrm{C}$, is shown in Figure 2 . At $475^{\circ} \mathrm{C}$, the stoichiometric samples have higher amounts of hardening than off-stoichiometric samples and the rate seems similar, though short aging time data is lacking. A similar behavior is observed at lower temperatures, which indicates stoichiometric samples experience a higher ordered phase fraction than off-stoichiometric samples. At $475^{\circ} \mathrm{C}$ the change in micro-hardness values tend to level off after 1000 hours, which indicates ordering transformation is approaching saturation. Considering the change of micro-hardness comes from ordering phase, lower amount of ordered phase has been formed in off-stoichiometric samples than in-stoichiometric samples. Based on the relationship between microhardness and ageing time, comparison of ordered phase fraction between all samples is $2.0>1.8 \approx 2.2>2.4$.

At medium $\left(418^{\circ} \mathrm{C}\right)$ and low $\left(373^{\circ} \mathrm{C}\right)$ aging temperatures, the kinetics are more sluggish than high temperature $\left(475^{\circ} \mathrm{C}\right)$ and resulting in less hardening, The relationship between microhardness and stoichiometry is more difficult to observe. At $418^{\circ} \mathrm{C}$, the hardening behavior is similar for all stoichiometries. Due to a higher aging temperature and higher diffusivity, the hardening rate is higher than that of $373^{\circ} \mathrm{C}$ but lower than $475^{\circ} \mathrm{C}$. The microhardness results for the samples aged at $373^{\circ} \mathrm{C}$, indicate slowest kinetics among the three temperatures.

The trend of hardening indicates that microhardness will reach saturation after 1,000 hours isothermal ageing at $475^{\circ} \mathrm{C}$, whereas the time to reach saturation for 418 and $373^{\circ} \mathrm{C}$ will be longer. Considering the hardening behavior of 418 and $373^{\circ} \mathrm{C}$ haven't reached saturation at 10,000 hours, additional agings will need to be performed. However, the following behavior of medium and low temperature to saturation can be predict by modeling, which will be discussed in next section. 


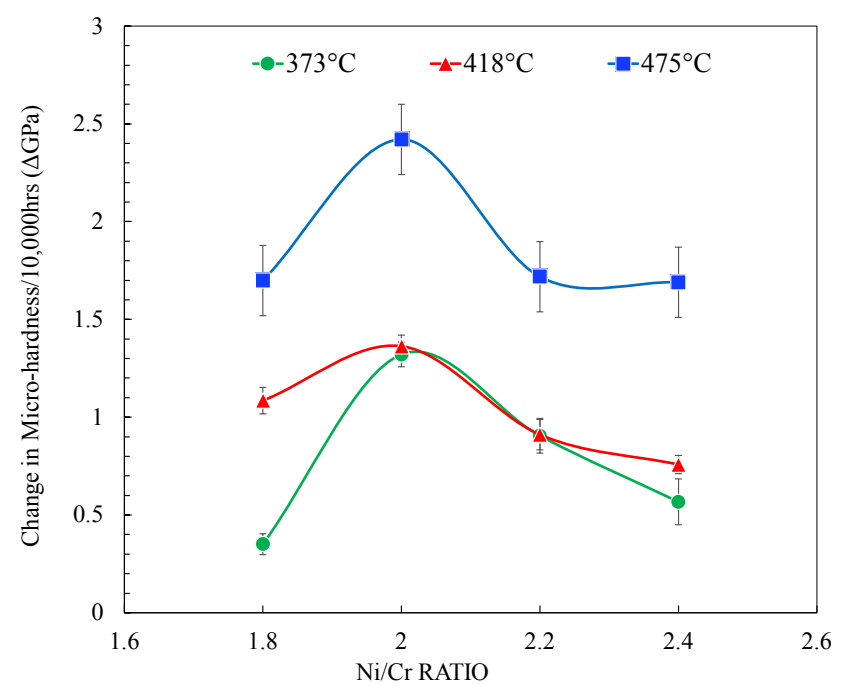

Figure 1. Change in microhardness after 10,000 hours aging for each stoichiometry as a function of temperature
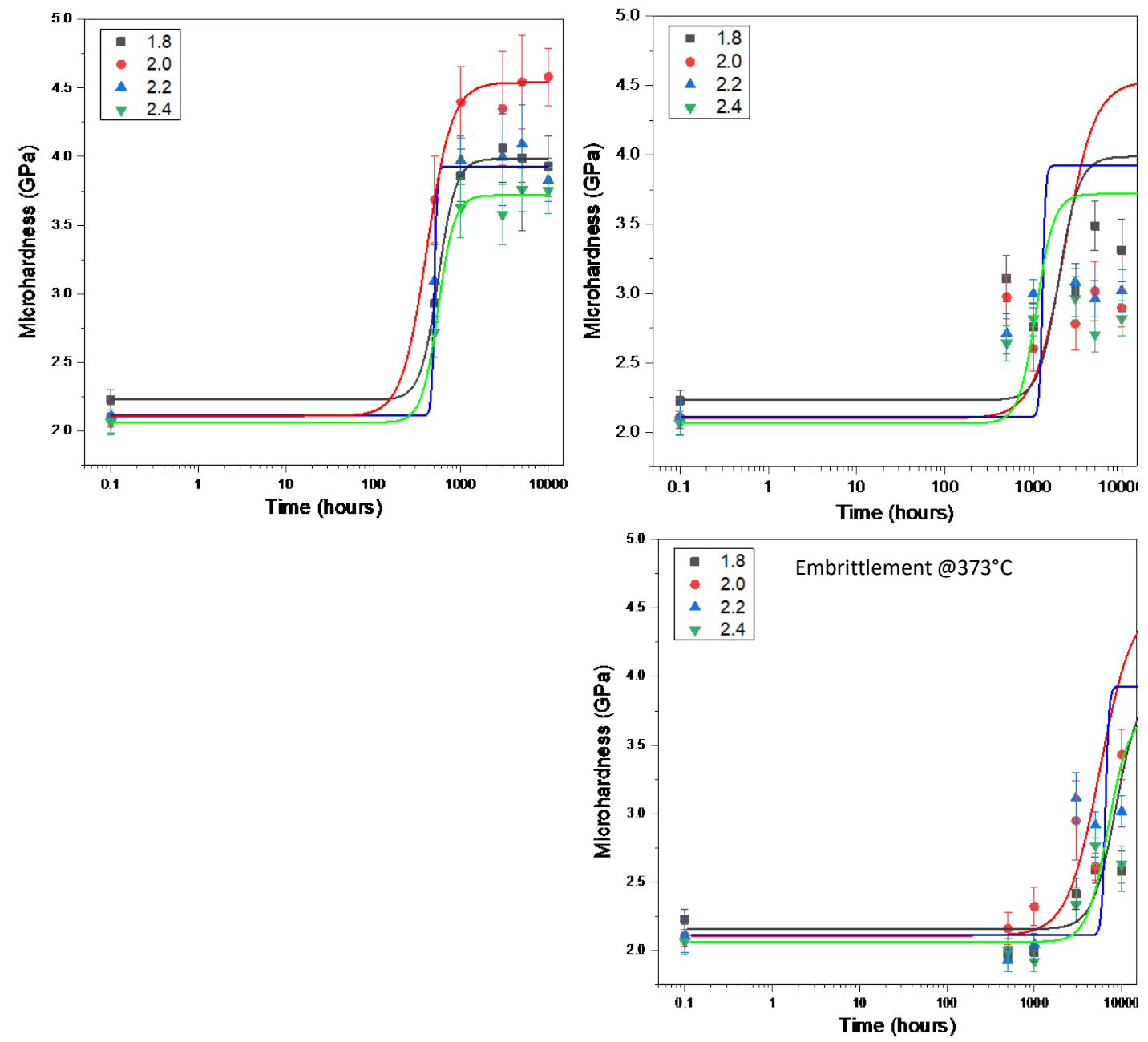

Figure 2. Microhardness of model alloys as a function of ageing time at three temperatures up to 10,000 hours isothermal ageing at 373,418 , and $475^{\circ} \mathrm{C}$ 


\section{$\underline{\text { APT of Model Alloys }}$}

APT data was collected from all NiCr alloys after aging for 10,000 hours. Each alloy shows evidence of phase decomposition via variations in reconstructed density and local ordering on (110) planes. Data analysis is challenged by technique artefacts and the details are still being developed to fully quantify and compare the different alloys.

\section{Micropillar Compression testing}

In order to explore the effects of ordered precipitate on mechanical properties, ex-situ micro-pillar compression test were performed to obtain yield strength and a failure behavior comparison before and after isothermal ageing. This work was not part of the original NEUP proposal but may serve to provide valuable information. The preliminary tests proved to be meritorious and additional testing will be pursued in future. Two samples were used in the preliminary experiments, unaged $\mathrm{Ni}: \mathrm{Cr}=2.0$ model alloy and the same alloy aged at $475^{\circ} \mathrm{C}$ for 10,000 hours to produce a saturated ordered structure.

The first step before milling micro-pillars is determining grain orientation. Figure 3 shows the EBSD map of the selected area. To simplify the effect of grain orientation on mechanical properties during compressing, all micro-pillars in current research are fabricated in grains near [001] orientation. After confirming grain orientation, next step is the fabrication of clearance area, which is of $100 \mu \mathrm{m}$ outer diameter, $30 \mu \mathrm{m}$ inner diameter and $15 \mu \mathrm{m}$ in depth, in "donut" shape for indenter tip. The milling procedure is shown in Figure 4. The third step is fabricating a square micro-pillar, which is in dimension of $5 \times 5 \times 12 \mu \mathrm{m}$, from the center section of "donut". To minimize the effect of $\mathrm{Ga}$ implantation on the mechanical properties of micro-pillar, a Pt protection layer in thickness of $0.5 \mu \mathrm{m}$ was deposited on the top surface of pillar (Figure 5).

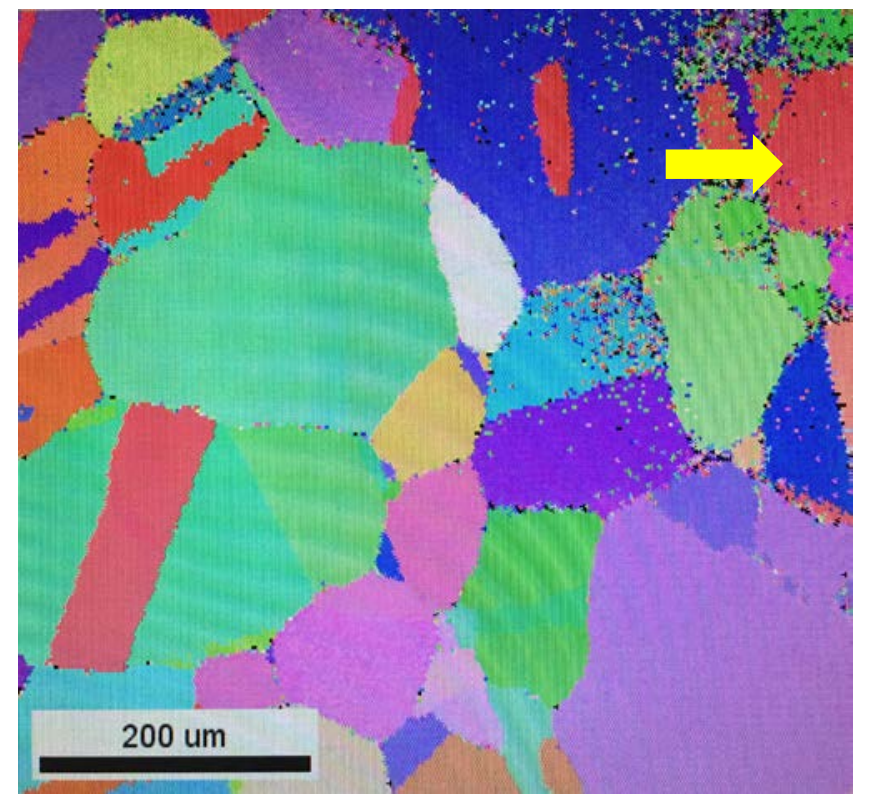

Figure 3. EBSD image of Ni2Cr-475-10000hr (target grain is marked out at right top corner of the EBSD map). 


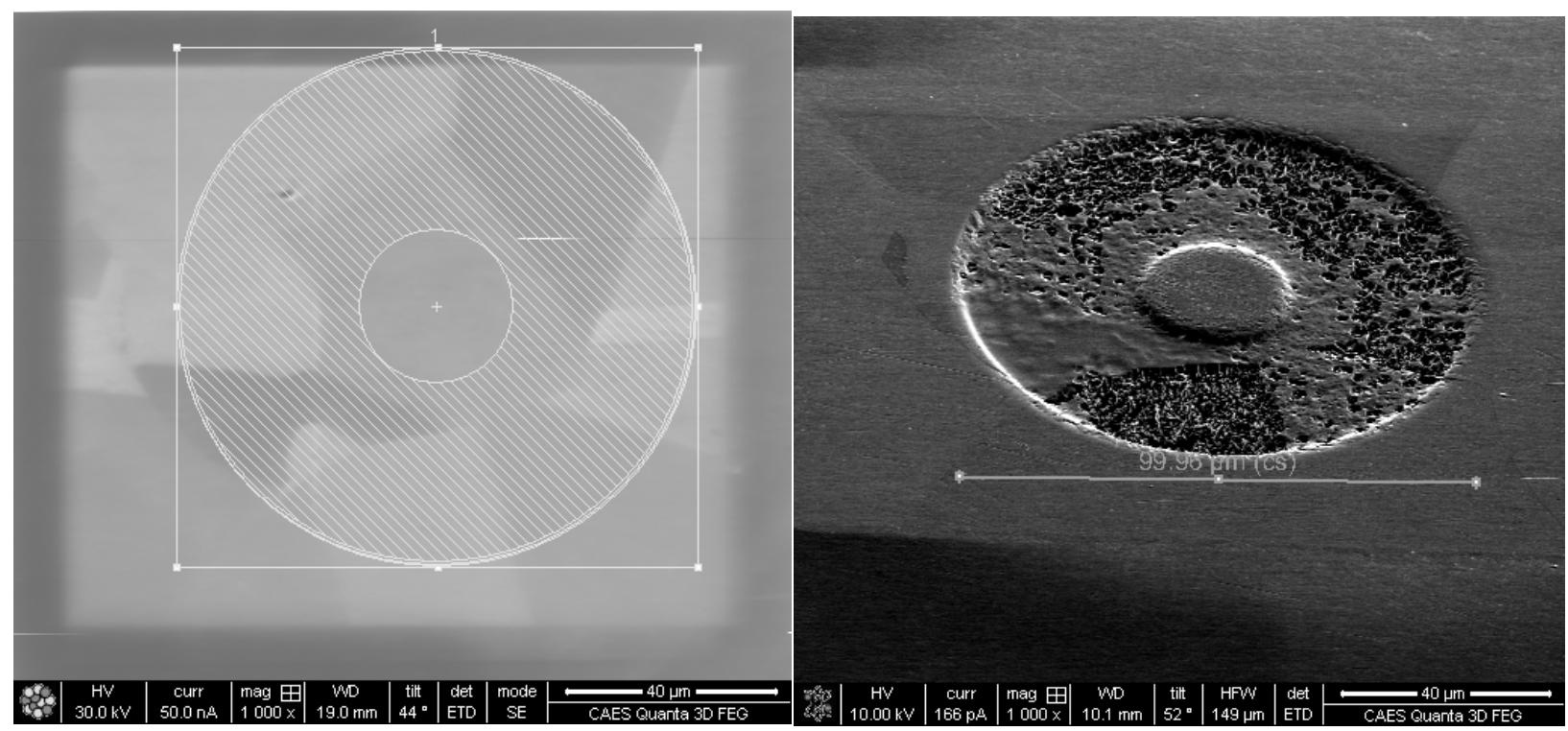

Figure 4. Fabrication of clearance for indenter tip (in progress).
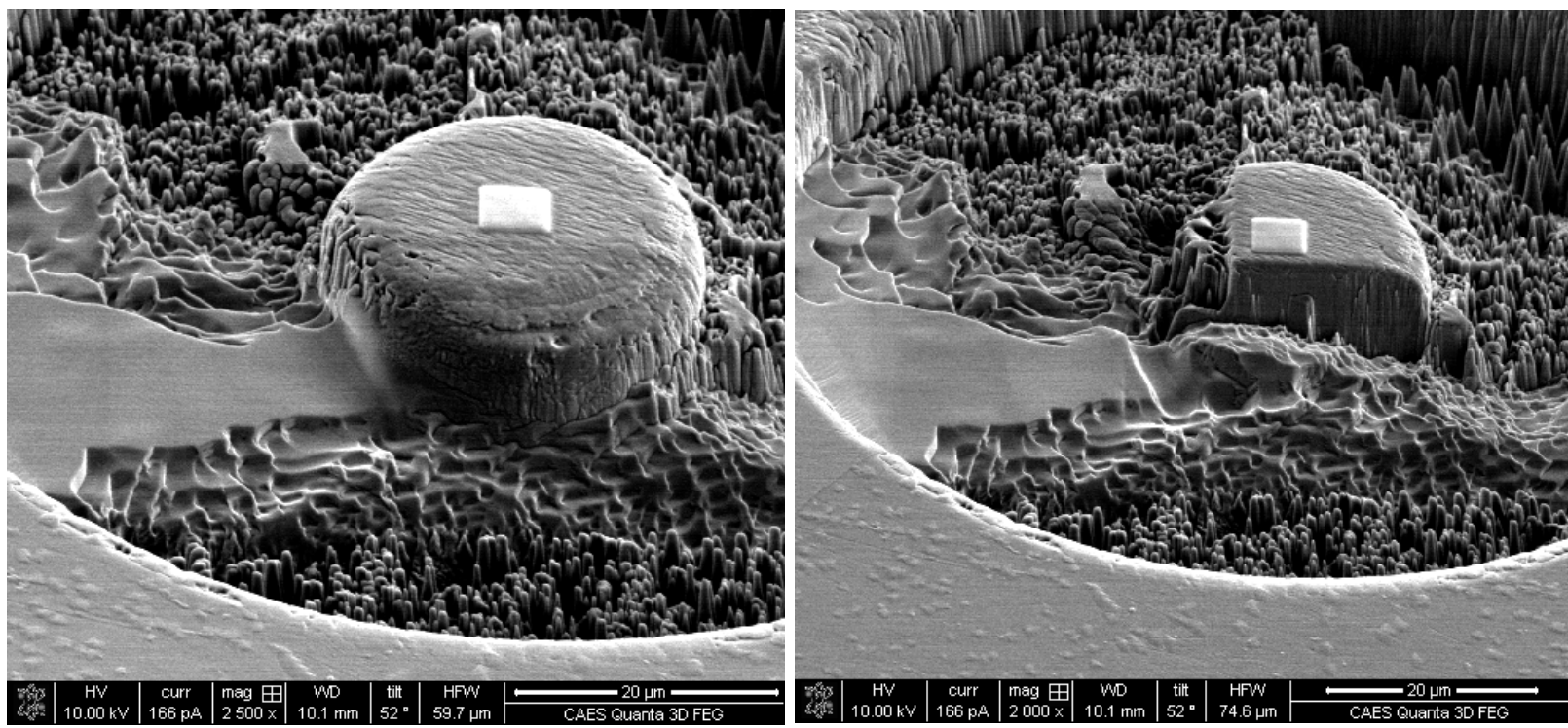

Figure 5. Square pillar fabricating in progress $(0.5 \mu \mathrm{m}$ Pt protection layer has been deposited on pillar top surface to minimize Ga implantation).

After fabricating of the micropillar, a lower voltage of ion beams are used to polish the pillar surface and sides to remove beam damage and taper angle on the outside of pillar. Figure 6 shows the final condition of micropillar after fabrication. After the fabrication of pillar, next step is performing nanoindentation on the pillar. 

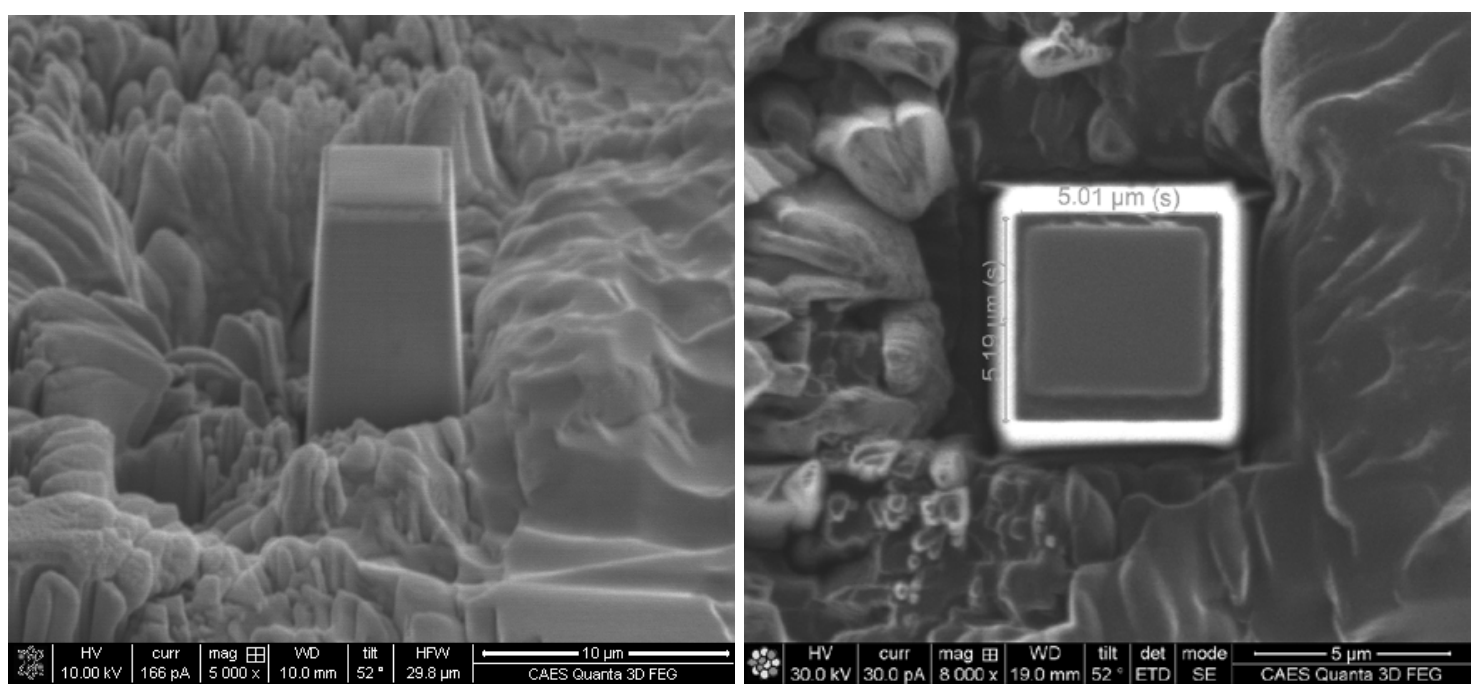

Figure 6. Final condition of the micro-pillar after polishing.

The compression test is performed on Hysitron nanoindenter (ex-situ) at Idaho National Laboratory. Load and displacement are controlled during compression. Figure 7 shows the shape of micropillars after compressing for unaged sample and aged sample. In the aged sample, only a few slip planes are active in an angle of $45^{\circ}$, while there are multiple slip parallel planes are active in a smaller angle in unaged sample. Considering the whole pillar was fabricated in a grain with [001] orientation, the active planes' orientation can be identified as [110], which is same as the orientation of ordered structure in $\mathrm{Ni}-\mathrm{Cr}$ system (planes of $\mathrm{Ni}$ and $\mathrm{Cr}$ align along the [110] direction). These preliminary results are interesting and more testing will be pursued in the future to clarify the correlation between the growth of ordering and orientation of active slip planes. 

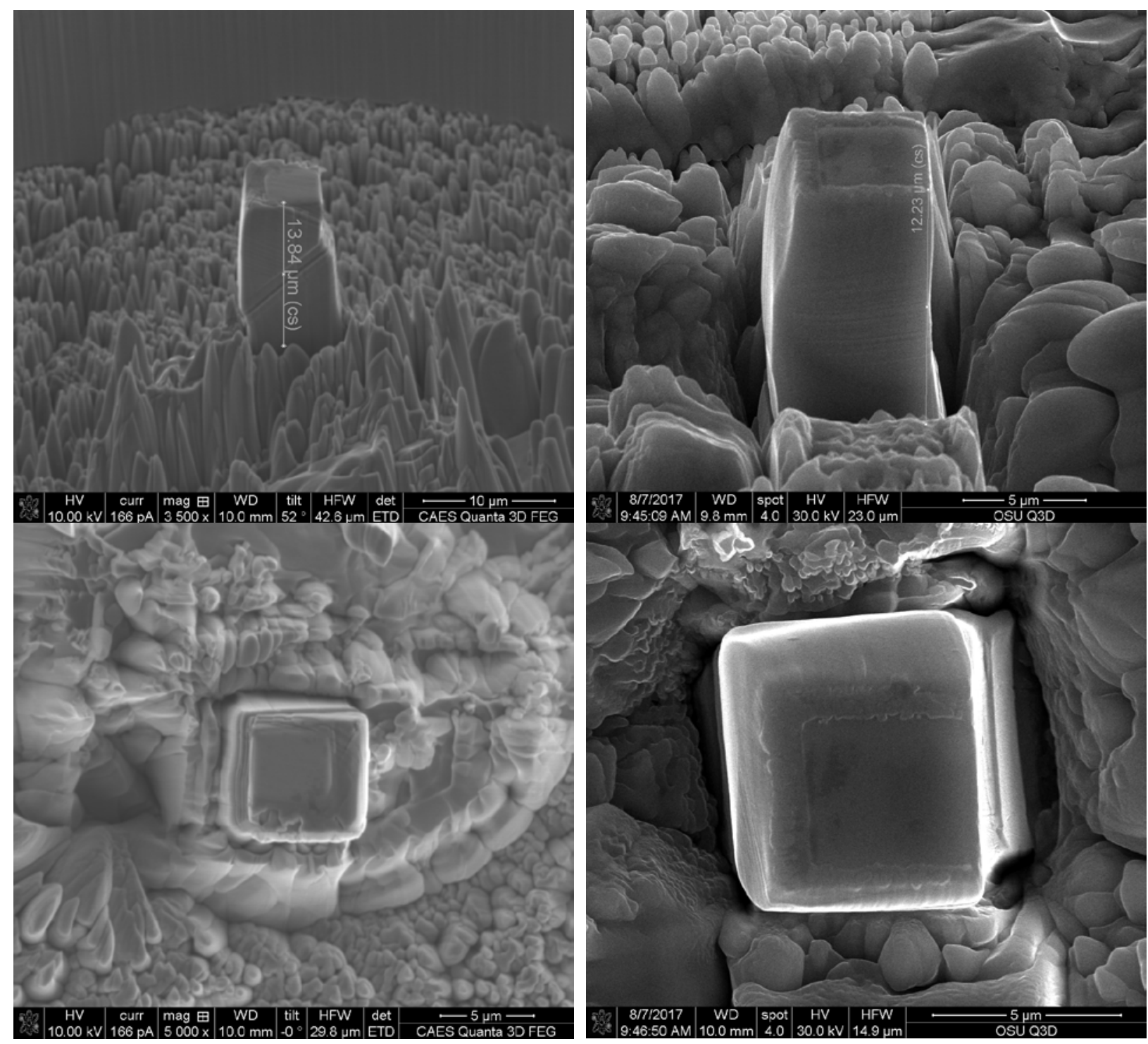

Figure 7. Geometry of micropillars after compressing (left: $\mathrm{Ni} 2 \mathrm{Cr}-475 \mathrm{C}-10000 \mathrm{hrs}$, right: $\mathrm{Ni2} C \mathrm{Cr}-$ unaged).

\section{$\underline{\text { SEM/TEM Characterization of Aged Model Alloys }}$}

The $\mathrm{Ni} / \mathrm{Cr}=2.0$ sample was aged for 5,000 hours at $475^{\circ} \mathrm{C}$ and characterized. SEM evaluation of this material revealed a coarse-grained recrystallized microstructure, with grain sizes varying from $\sim 70$ to $360 \mu \mathrm{m}$. TEM analysis confirmed that precipitation had occurred during ageing at $475^{\circ} \mathrm{C}$. Selected area electron diffraction revealed the presence of $\mathrm{Ni}_{2} \mathrm{Cr}$ precipitates. The size and morphology of the $\mathrm{Ni}_{2} \mathrm{Cr}$ precipitates was assessed using centered dark-field TEM images, an example of which is shown in Figure 8. These nanoscale precipitates were approximately 1 to 4 $\mathrm{nm}$ in size, and exhibited an irregular morphology. These $\mathrm{Pt}_{2} \mathrm{Mo}$-ordered body centered orthorhombic precipitates were crystallographically related to the fcc matrix, as shown in the $[100]_{\text {matrix }+\mathrm{Ni2Cr}}$ selected area electron diffraction pattern in Figure 8. 

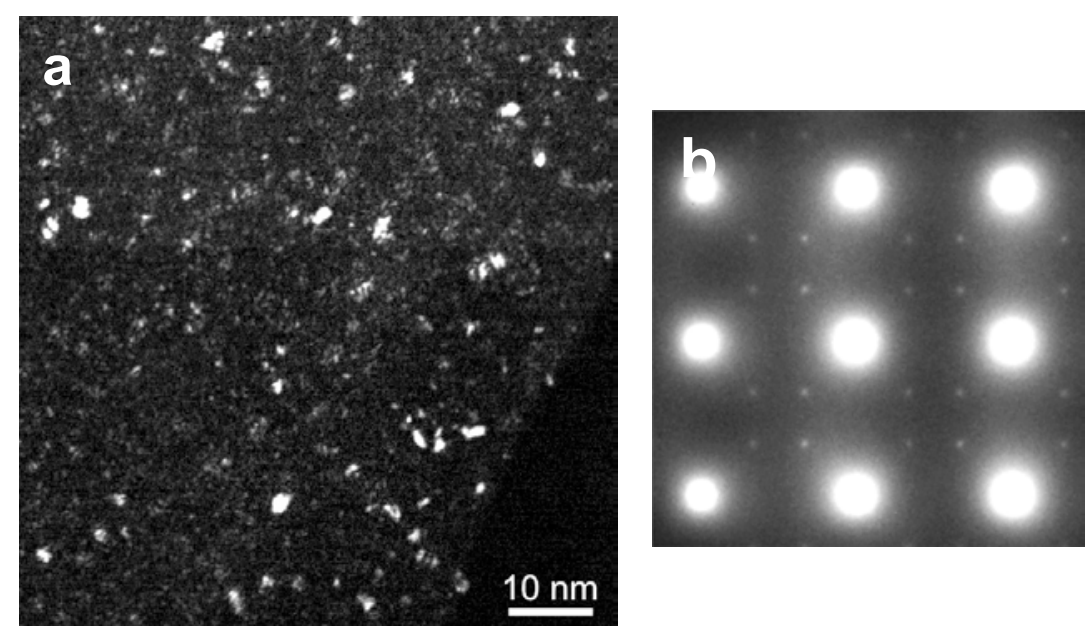

Figure 8. (a) Centred dark-field TEM image of the ultrafine $\mathrm{Ni}_{2} \mathrm{Cr}$ precipitates formed in the $\mathrm{Ni}-$ $33 \% \mathrm{Cr}$ alloy after ageing for $5000 \mathrm{~h}$ at $475^{\circ} \mathrm{C}$. (b) Corresponding [100] selected area electron diffraction pattern showing the precipitate reflections for the body-centred orthorhombic structure.
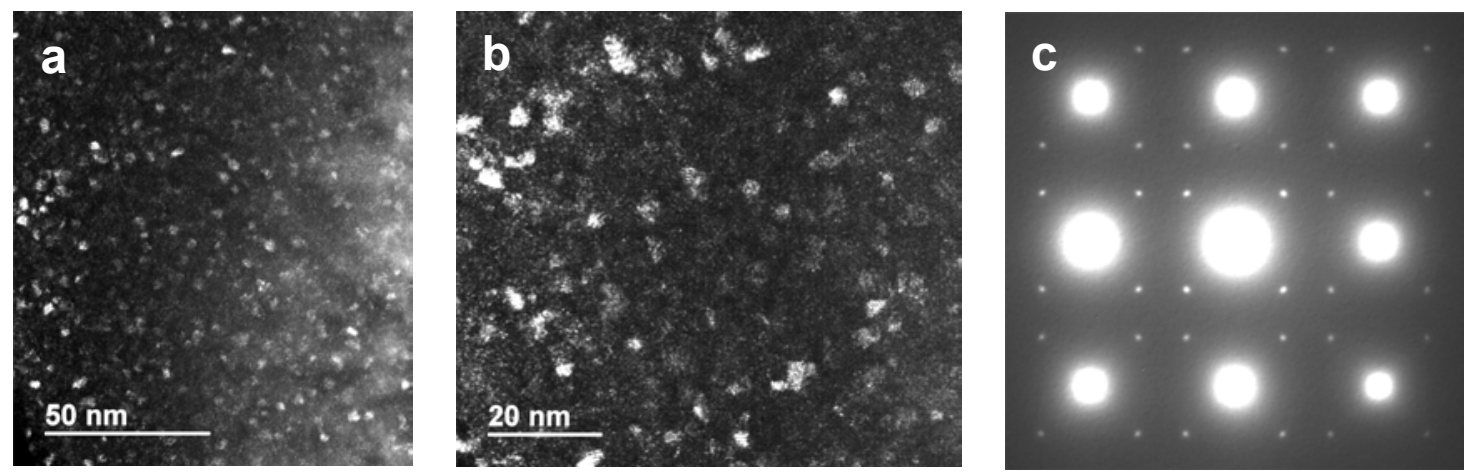

Figure 9. (a) Centred dark-field TEM image of the ultrafine $\mathrm{Ni}_{2} \mathrm{Cr}$ precipitates formed in the $\mathrm{Ni}$ $30 \%$ at. $\mathrm{Cr}(\mathrm{Ni} / \mathrm{Cr}=2.4)$ alloy after ageing for $10,000 \mathrm{~h}$ at $475^{\circ} \mathrm{C}$. (b) Higher magnification centered dark-field TEM image of the $\mathrm{Ni}_{2} \mathrm{Cr}$ precipitates. Corresponding [100] selected area electron diffraction pattern showing the precipitate reflections for the body-centred orthorhombic structure.

The $\mathrm{Ni} / \mathrm{Cr}=2.4$ sample was aged 10,000 hours at $475^{\circ} \mathrm{C}$ and characterized. The general microstructure of this alloy was similar to the $\mathrm{Ni} / \mathrm{Cr}=2$ alloy, with a similar range of grain sizes $(\sim 70$ to $360 \mu \mathrm{m})$. Selected area electron diffraction confirmed the presence of ordered body centered orthorhombic $\mathrm{Ni}_{2} \mathrm{Cr}$ precipitates. TEM characterization of this aged alloy revealed the presence of a uniform distribution of very fine ( $\sim 2$ to $5 \mathrm{~nm}$ in size) $\mathrm{Ni}_{2} \mathrm{Cr}$ precipitates. The irregular morphology of these nanoscale precipitates was similar to those in the stoichiometric alloy. Representative centered dark-field TEM images and the [100] matrix $+\mathrm{Ni2}$ Cr selected area electron diffraction pattern are shown in Figure 9.

TEM specimens were examined in the FEI Talos F200 advanced analytical S/TEM with 4 Silicon drift detectors for energy dispersive X-ray spectroscopy to assess the composition of the nanoscale precipitates. However, the analysis of these nanoscale precipitates was complicated by the 
topography of the electropolished thin-foil specimens, so that it was not possible to detect the nanoscale compositional variations associated with precipitation. Work is continuing to optimize TEM specimens and to use high resolution STEM imaging for more detailed characterisation of the $\mathrm{Ni}_{2} \mathrm{Cr}$ precipitates.

\subsubsection{Commercial alloys}

Commercial Alloys 690, 625 and 625+ and being isothermally aged at four temperatures for $10,000+$ hours. Commercial alloys have more sluggish ordering kinetics than model alloys. This is primarily because the addition of Fe lowers the critical temperature of the ordered phase and peak ordering temperature lowers, resulting in lower diffusion. The alloys will reach the first aging check point of 10,000 hours of aging time in December 2017.

\section{$\underline{\text { SEM/TEM Characterization of As-Received Commercial Alloys }}$}

Alloy 690

This alloy exhibited a fully-recrystallized, equiaxed grain structure with grain sizes ranging from $\sim 50$ to $90 \mu \mathrm{m}$, and numerous annealing twins. Discrete darkly-imaging intergranular carbides were readily visible throughout the microstructure. The backscattered electron (BSE) images in Figure 10 show the range of microstructural features. Numerous coarse inclusion were also detected throughout the alloy. SEM-EDX spectrum image datasets confirmed the presence of TiN inclusions and $\mathrm{Cr}$-rich carbides. TEM characterization of electron-transparent thin-foil samples confirmed the presence of intergranular $\mathrm{Cr}$-rich $\mathrm{M}_{23} \mathrm{C}_{6}$ carbides throughout the material. Fine plate-like $\mathrm{M}_{23} \mathrm{C}_{6}$ were observed along incoherent twin boundary segments whereas coarser (up to several microns in size) carbides had formed along high angle grain boundaries. All fcc $\mathrm{M}_{23} \mathrm{C}_{6}$ carbides were semi-coherent with the matrix and exhibited the classical "cube-cube" orientation relationship with the fcc matrix. This is illustrated in the selected area electron diffraction pattern shown in Figure 10.

\section{Alloy 625 (heat 602051) - Low Strength Condition}

The as-received alloy was characterized by an equiaxed grain structure, with a non-uniform distribution of grain sizes ranging from $\sim 5$ to $50 \mu \mathrm{m}$. Numerous brightly-imaging (high $\mathrm{Z}$ contrast) inclusions ranging in size from approximately 0.5 to $10 \mu \mathrm{m}$ were observed in the BSE images. More detailed examination also revealed the presence of $\mathrm{Cr}$ - and Mo-rich carbides at grain boundaries. Figure 11 contains several BSE images of the as-received Alloy 625 microstructure and SEM-EDX maps obtained from several coarse $\mathrm{Nb}$-Ti carbontride inclusions.

TEM characterization of this alloy revealed a variable microstructure in terms of deformation substructure, with some areas containing low proportions of dislocations whereas other specimens showed evidence of local deformation/cross-slip, Figure 12. This suggests that some deformation had occurred at elevated temperature, possibly during prior processing of the alloy. Selected area electron diffraction confirmed that there were no $\gamma^{\prime \prime}$ precipitates in this alloy. 

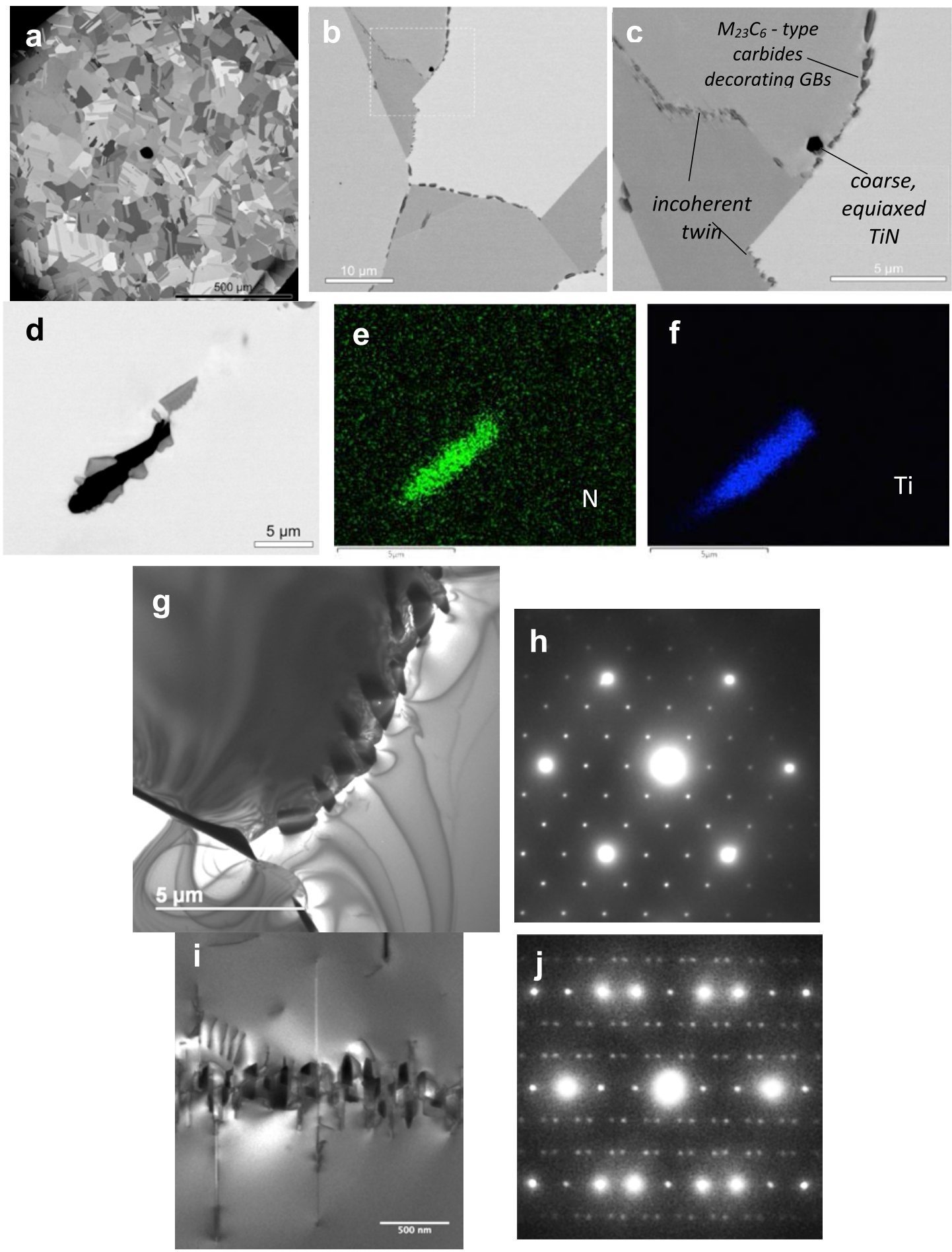

Figure 10. (a)-(c) BSE images showing the general structure and distribution of intergranular carbides in the as-received Alloy 690 material. (d)-(f) Corresponding EDX maps for $\mathrm{N}$ and Ti. (g), (i) Bright-field TEM images showing the extent of intergranular $\mathrm{M}_{23} \mathrm{C}_{6}$ precipitation on high angle grain boundaries and incoherent twin boundaries, respectively. (h),(j) Corresponding [110] SADPs showing the "cube-cube" orientation relationship between the fcc $\mathrm{M}_{23} \mathrm{C}_{6}$ carbides and the fcc matrix. Note the twinned matrix pattern in $(j)$ associated with the two twin-related grains. 

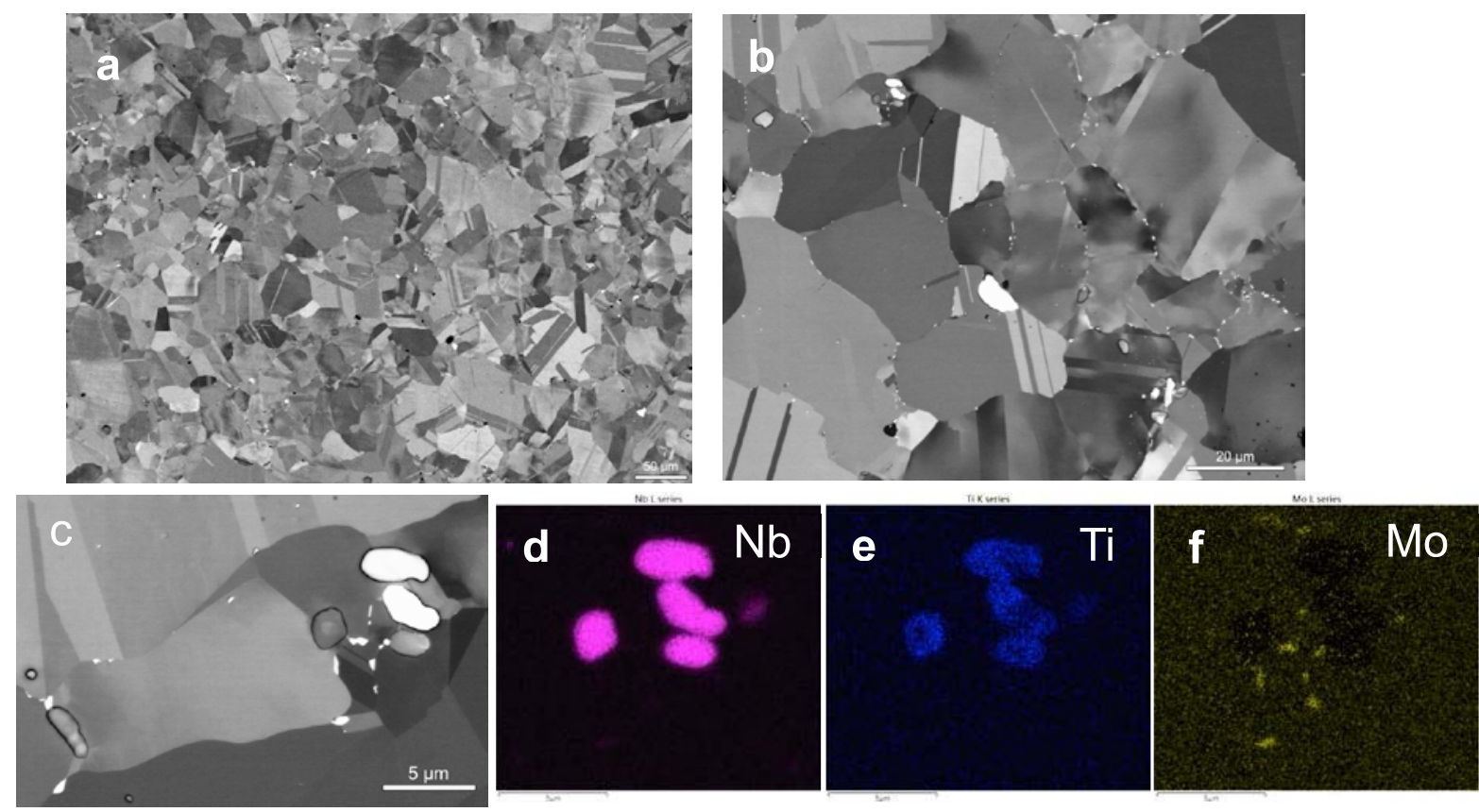

Figure 11. (a)-(b) BSE images showing the variation in grain size observed for the as-received Alloy 625 (low strength) material. (c)-(e) BSE image and corresponding SEM-EDX maps for $\mathrm{Nb}$, and $\mathrm{Ti}$, respectively, obtained from the coarse $\mathrm{Nb}$ - Ti carbonitride inclusions. (f) Mo EDX map showing the location of Mo-enriched carbides in the vicinity of the inclusions.
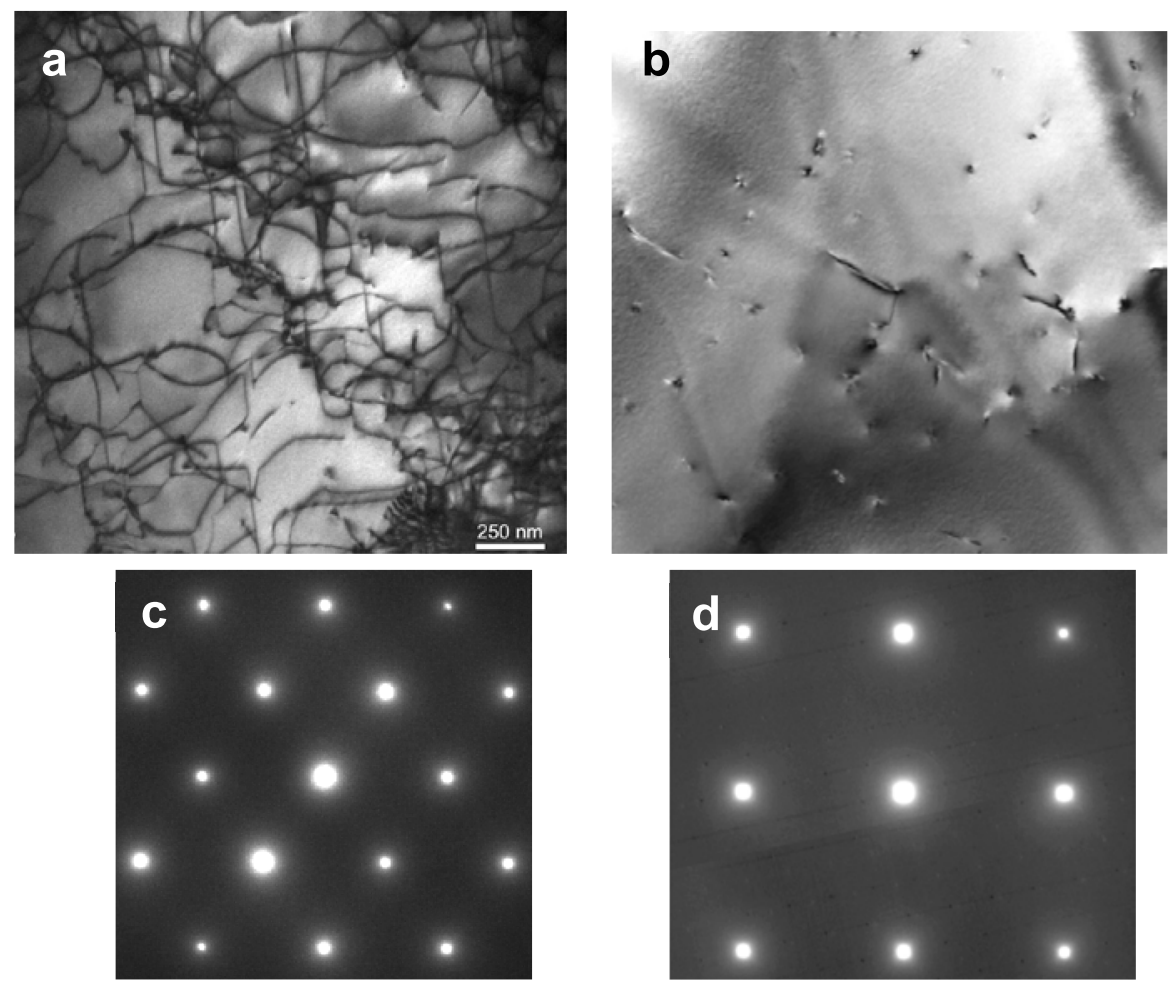

Figure 12. (a)-(b) Bright-field TEM images showing the variation in dislocation content within the low strength as-received Alloy 625 material. (c)-(d) Corresponding [110] and [100] selected area electron diffraction patterns. Note the absence of any $\gamma^{\prime \prime}$ precipitate reflections. 
The general microstructure of the aged Alloy 625 material was very similar to the as-received low strength alloy. No grain growth had occurred during the $650^{\circ} \mathrm{C}$ ageing treatment. Detailed microstructural analysis revealed that intergranular precipitation had occurred, as shown in the BSE images of Figure 13. Discrete brightly-imaging intergranular precipitates enriched in $\mathrm{Nb}(\delta$, $\mathrm{Ni}_{3} \mathrm{Nb}$ ) had formed along high angle grain boundaries. TEM characterization confirmed that extensive $\gamma^{\prime \prime}$ precipitation had occurred, as well as intergranular $\mathrm{Cr}$-rich $\mathrm{M}_{23} \mathrm{C}_{6}$ carbides. These disc-shaped precipitates, which form on the $\{100\}$ planes in the matrix, were approximately 100 to $120 \mathrm{~nm}$ in "length" (disc diameter) and $\sim 20$ to $25 \mathrm{~nm}$ in thickness. The three variants of the $\gamma^{\text {" }}$ precipitates are visible in the centered dark-field TEM image (and associated [100] SADP) in Figure 13.
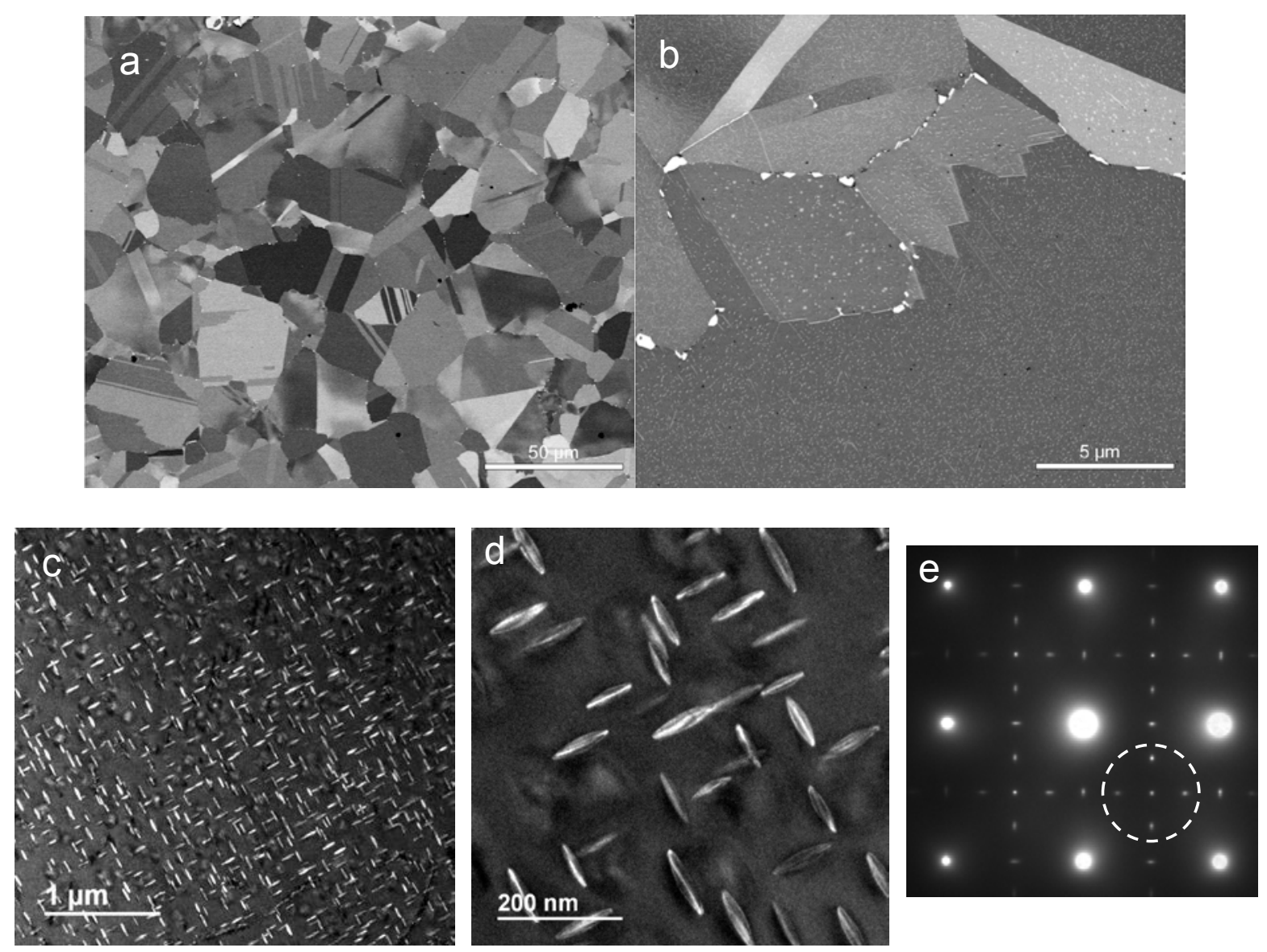

Figure 13. (a)-(b) BSE images of Alloy 625 aged at $650^{\circ} \mathrm{C}$ for $100 \mathrm{~h}$. Note the presence of brightly-imaging intergranular precipitates $\left(\delta \mathrm{Ni}_{3} \mathrm{Nb}\right)$. (c)-(d) Centered dark-field TEM images showing 2 disc-on-edge variants of the $\gamma^{\prime \prime}$ precipitates in a [100]-oriented grain. The third variant is parallel to the foil surface. (e) [100] SADP showing the 3 variants of the $\gamma^{\prime \prime}$ precipitates. 
The Alloy 625+ material was provided in an aged condition. The alloy was characterized by a recrystallized microstructure, with numerous annealing twins, as shown in the BSE image of Figure 14 (a). The grain size ranged from $\sim 50$ to $160 \mu \mathrm{m}$. Within this recrystallized structure were numerous coarse $(\sim 10 \mu \mathrm{m} \max )$ inclusions, the majority of which were $\mathrm{MN}$ with $\mathrm{M}=\mathrm{Ti}$ and $\mathrm{Nb}$. It was noted that the inclusion/matrix was frequently the site of Mo-enriched carbide precipitation. This alloy contained a high proportion of fine $(\sim 20 \mu \mathrm{m}$ in diameter $) \gamma^{\prime \prime}$ precipitates. These $\mathrm{DO}_{22}$-ordered precipitates are clearly evident in the centered dark-field TEM images with corresponding [100] SADP in Figure 14. Unlike the conventional high strength (aged) Alloy 625, the Alloy $625+$ material exhibited $\delta$ precipitation along incoherent twin boundaries. This was accompanied by the formation of a very narrow $\mathrm{Nb}$-depleted $\gamma^{\prime \prime}$ precipitate-free zone.

This alloy has been sectioned and polished, and will be sent to Prof. Emmanuelle Marquis for proton irradiation in the Michigan Ion Beam Laboratory to assess the stability of the $\gamma^{\prime \prime}$ precipitates and the formation of the $\mathrm{Ni}_{2} \mathrm{Cr}$ precipitates. 

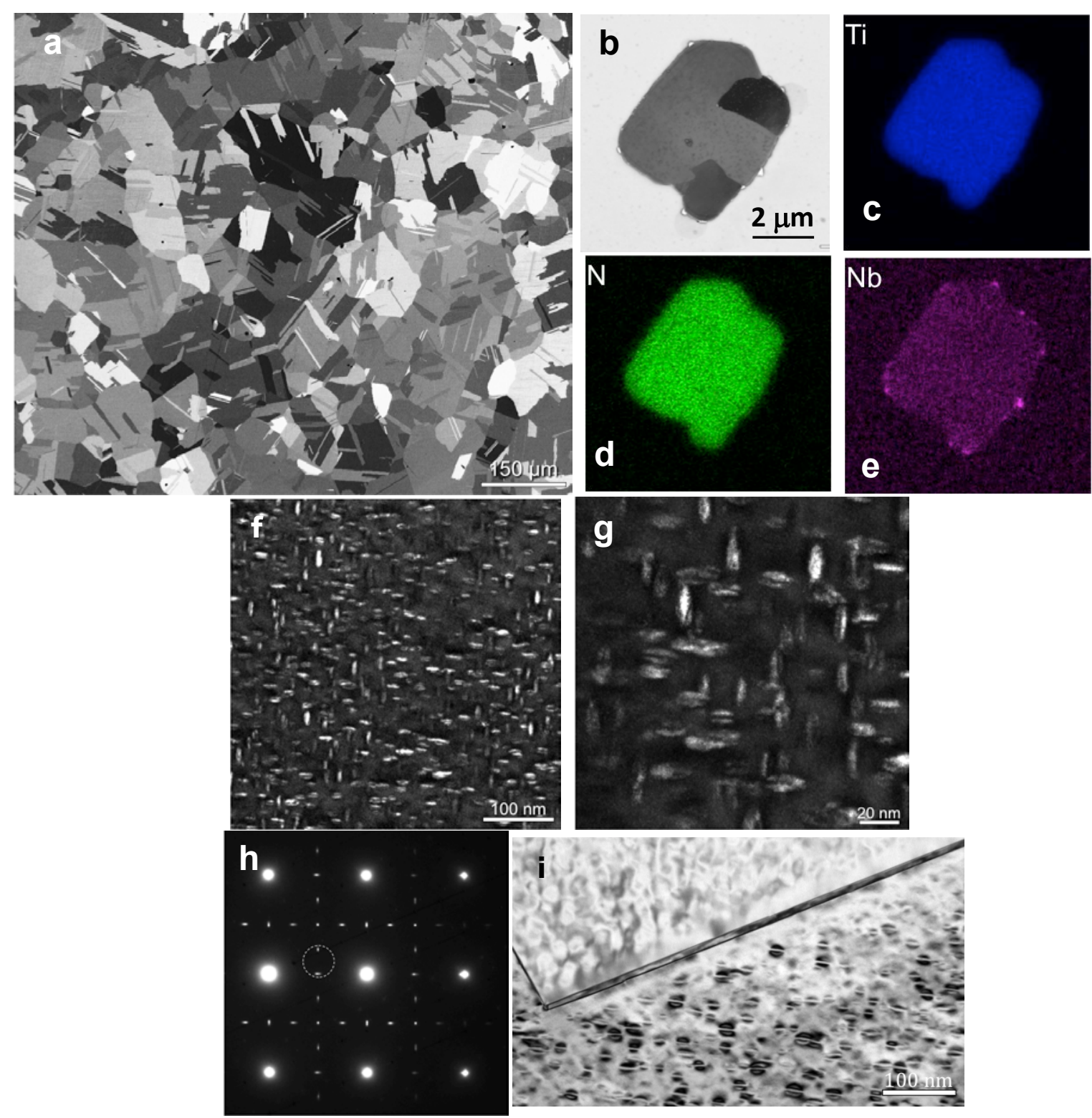

Figure 14. (a) BSE image showing the general microstructure and grain size variation in the Alloy 625+ material. (b) BSE image and corresponding EDX elemental maps for (c) Ti, (d) N, and (e) $\mathrm{Nb}$ associated with a coarse Ti-rich $\mathrm{M}(\mathrm{CN})$ inclusion. Note the preferential precipitation of $\mathrm{Nb}$-rich precipitates at the inclusion/matrix interface. (f)-(g) Centered dark-field TEM images showing 2 variants of the $\gamma^{\prime \prime}$ precipitates. (h) [100] SADP with $\gamma^{\prime \prime}$ reflections. (i) BF TEM image of $\delta$ along incoherent twin boundary.

\subsubsection{Characterization of Irradiated alloys}

Little has been reported on the irradiation behavior of Alloys 625 and 690. Here, APT characterization of the irradiated alloys was performed after ion and proton irradiations of Alloys 625 and $625+$ in their annealed and aged condition $\left(650^{\circ} \mathrm{C}\right.$ for 25 and 100 hours respectively) and 
Alloy 690 in its annealed condition. Preliminary observations suggest the formation and development of the following microstructural features:

- $\mathrm{B}, \mathrm{P}$, and $\mathrm{Ci}$ co-cluster and the extent of clustering may be dose rate dependent. In Alloy $625+$, clusters were observed after proton irradiation at $10^{-5} \mathrm{dpa} / \mathrm{s}$ but not after ion irradiation at $10^{-4} \mathrm{dpa} / \mathrm{s}$. (Figure $15 \mathrm{~A}$ ). The estimated number density is $1 \times 10^{22} / \mathrm{m}^{3}$.

- $\mathrm{Al}, \mathrm{Ti}$, and $\mathrm{Nb}$, that are present in Alloys 625,625+, and 690, exhibit very fine uniform clustering (Figure 15B).

- Ordering of $\mathrm{Ni}$ and $\mathrm{Cr}$ was also evident after proton irradiation but not after ion irradiation (Figure 15C).

- In the case of aged alloys with $\gamma^{\prime \prime}$ precipitates (aged 625 and 625+), partial dissolution of the precipitate was observed (Figure 15D).

- In Alloy 690, Si segregation to dislocation loops is observed after irradiation. The loops appear enriched in $\mathrm{Si}$ and depleted in $\mathrm{Cr}$ and $\mathrm{Fe}$. Dose rate appears to affect the loop density and extent of segregation (Figure 15E). TEM analyses are being performed on confirm and further quantify the development of a dislocation structure during irradiation.

APT data collection on the irradiated model alloys is ongoing and the observations will be reported in a future report.
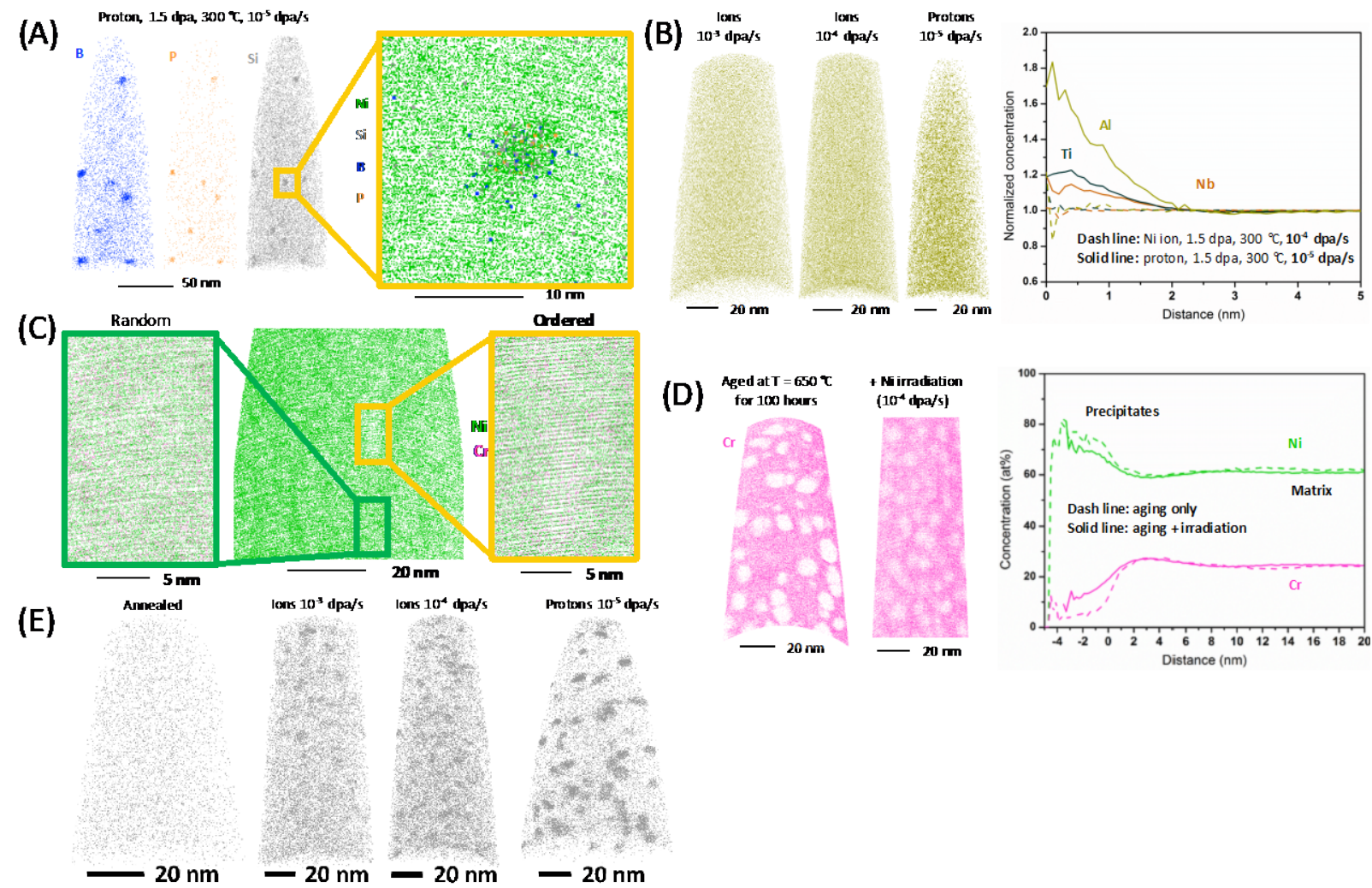

Figure 15. Representative examples of irradiation-induced features in Alloys 625, 625+, and 690 after irradiations at $300^{\circ} \mathrm{C}$ to a dose of $1.5 \mathrm{dpa}$. (A) B, P, and Si co-clusters in Alloy 625+ after proton irradiation but also present in all three alloys; (B) $\mathrm{Al}, \mathrm{Ti}, \mathrm{Nb}$ fine co-clustering observed after proton irradiation. The same behavior is observed for the other two alloys. (C) $\mathrm{Ni}$ and $\mathrm{Cr}$ ordering in Alloy 625+ after proton irradiation; (D) $\gamma^{\prime \prime}$ dissolution after ion irradiation (E) $\mathrm{Si}$ segregation to dislocation in Alloy 690. 


\subsubsection{Thermal modeling in Grizzly}

Grizzly is a multiphysics simulation code under development at Idaho National Laboratory to simulate aging mechanisms and their effects on the integrity of critical LWR components, including Ni-Cr alloy components. Predictions of the LWR component integrity rely on the ductile-to-brittle transition temperature (DBTT) curve to determine the toughness of the alloy after a period of exposure to in-service reactor conditions. The macroscopic DBTT curve is governed by the microstructure evolution of the alloys, thus, a capability to predict the microstructure evolution in response to thermal ageing is being implemented into Grizzly.

The same capabilities that are being developed for RPV steels can also be adapted for modeling the evolution of engineering properties due to microstructure evolution in Ni-Cr alloys. As described here, the Avrami equation can be used to represent the evolution of long range ordering, which can in turn be used as input in a crystal plasticity model in Grizzly. The parameters for the Avrami equation can be provided by a combination of results from atomistic kinetic Monte Carlo (AKMC) simulations of long range ordering and experimental studies. The crystal plasticity model predicts the yield strength and hardening behavior of the aged alloy considered - quantities that are of interest for their effect on engineering behavior. The work described here is an initial demonstration of the application of the Avrami and crystal plasticity models in Grizzly to prediction of engineering behavior of Ni-Cr alloys.

\section{$\underline{\text { Avrami Equation Implementation }}$}

The results of the AKMC simulations can be extended to a larger sample volume through the use of the Avrami equation [4]. The Avrami equation, also known as the Kolomogorov-Johnson-MehlAvrami (KJMA) equation, is used to estimate the fraction of precipitate concentration, assuming random and homogeneous nucleation and isotropic precipitate growth. Young and Eno have shown that the KJMA equation can be used to estimate the transformed fraction of long-range ordered phase precipitates in $\mathrm{Ni}-\mathrm{Cr}$ alloys under various cooling treatments [5]:

$$
f=1-\exp \left(-(k t)^{n}\right) \quad k=k_{o} \exp \left(\frac{-Q}{R T}\right)
$$

where $t$ is the conditioning time and $T$ is the conditioning temperature. The total phase fraction of long-range ordered precipitates is used in continuum level simulations of aged $\mathrm{Ni}_{2} \mathrm{Cr}$ alloys, and the KJMA equation can be used to calculate this initial condition value.

Within the Grizzly code, the KJMA equation is implemented as a standalone function. The KJMA equation function can be called at various times during a simulation, and it can be used for a variety of purposes. To match the cooling treatment used in the micropillar and hardness experiments conducted on the $\mathrm{Ni}_{2} \mathrm{Cr}$ alloy, the parameters for furnace cooled $\mathrm{Ni}_{2} \mathrm{Cr}$ are used to verify the Grizzly implementation of the KJMA equation. 
Table 6. Parameters used in the KJMA equation for furnace cooled $\mathrm{Ni}_{2} \mathrm{Cr}$ alloy [5]

\begin{tabular}{cc}
\hline Parameter Description & Parameter Value \\
\hline Initial growth factor $(\mathrm{ko})$ & $244.0 \mathrm{e} 3(1 / \mathrm{s})$ \\
Apparent activation energy $(\mathrm{Q})$ & $8.33 \mathrm{e} 11(\mathrm{~J} / \mathrm{mol})$ \\
Universal gas constant $(\mathrm{R})$ & $8.314(\mathrm{~J} / \mathrm{mol}-\mathrm{K})$ \\
Avrami exponent $(\mathrm{n})$ & $0.65(-)$ \\
\hline
\end{tabular}

The verification testing spanned a time range from 0.1 hours to 10,000 hours. The series of verification simulations were run at $475^{\circ} \mathrm{C}$ to match the condition of the $\mathrm{Ni}_{2} \mathrm{Cr}$ alloy used in the micropillar tests. The results of the Grizzly KJMA equation implementation, shown in Figure 16, demonstrate the expected S-shaped curve in response to increasing ageing time on the fraction of long-range ordered precipitates in the alloy.

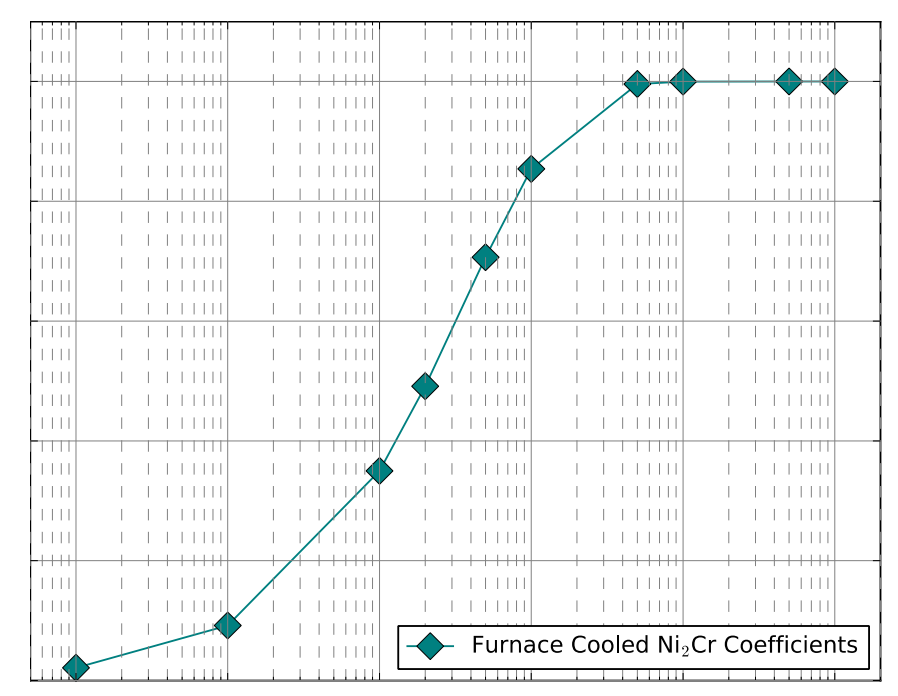

Figure 16. Verification simulation results of the KJMA equation implementation in Grizzly of $\mathrm{Ni}_{2} \mathrm{Cr}$ aged at $475^{\circ} \mathrm{C}$

The output of the KJMA equation, the transformed fraction of long range ordered precipitates, can be used to calculate the number density of these precipitates in an alloy exposed to a conditioning temperature for a given amount of time. The precipitate number density, along with an assumed average diameter of $2-3 \mathrm{~nm}$, is a required initial condition for the mesoscale crystal plasticity model.

\section{Crystal Plasticity Model Evaluation}

Dislocation based crystal plasticity models calculate the plastic strain within a metal as a function of mobile dislocation glide. As such, these mesoscale models can function as a bridge to connect microstructure evolution models, such as the AKMC simulations, to macroscale models of the DBTT and fracture. The toughness of a material, which governs the macroscale fracture behavior, is a function of both elastic deformation and plastic deformation. While yield stress measurements 
capture the elastic contribution to a material's toughness, information about the dislocation movement is required to understand the plastic component of toughness.

Crystal plasticity models enable the simulation of this plastic behavior by tracking dislocation movement and the interaction of these dislocations with crystal defects, such as the long-range ordered precipitates. Crystal plasticity models additively decompose the deformation gradient into elastic and plastic components, and define the plastic velocity gradient as the sum of the dislocation slip on each slip system:

$$
L^{p}=\Sigma_{\alpha} \gamma^{(\alpha)} \hat{s}^{(\alpha)} \otimes \hat{m}^{(\alpha)}, \quad \dot{\gamma}^{(\alpha)}=\rho_{m}^{(\alpha)} b v=\rho_{m}^{(\alpha)} b v_{o}\left|\frac{\tau^{(\alpha)}}{g_{\text {total }}^{(\alpha)}}\right|^{1 / m} \operatorname{sign}\left(\tau^{(\alpha)}\right)
$$

Dislocation density based models define the plastic slip, $\gamma^{(\alpha)}$, as a function of the mobile dislocation density, $\rho^{(\alpha)} \mathrm{m}$, and the dislocation glide velocity, $v$. The unit vectors, $s^{(\alpha)}$ and $m^{(\alpha)}$, give the slip direction and the slip plane normal for each slip system in the crystal. The dislocation glide velocity can be defined either as a power law function, shown above with the strain rate sensitivity exponent $m$, or as an exponential term. The driving force for the dislocation glide velocity is the ratio of the applied shear stress on each slip system, $\tau^{(\alpha)}$, and the resistance of each slip system to dislocation glide, $\mathrm{g}^{(\alpha)}$. The slip system resistance is often termed the strength of the slip system. Because the power law definition of dislocation glide velocity provides more numerical stability, that definition is used in the crystal plasticity model efforts described below.

Resistance to dislocation motion on each of the slip systems within the crystal plasticity is modeled as the sum of hardening contributions from the intrinsic lattice resistance to slip, the resistance to dislocation motion from the forest of other dislocations in the material, and the resistance from precipitates.

$$
g_{\text {total }}^{(\alpha)}=g_{P N}^{(\alpha)}+\alpha_{B H} b \mu \sqrt{\Sigma_{m} \Omega^{(m \alpha)} \rho^{(\alpha)}}+\alpha_{D B H} b \mu \sqrt{d N}
$$

The initial or intrinsic lattice resistance, $\mathrm{g}^{(\alpha)} \mathrm{PN}$, is the Peierls-Nabarro stress. The contribution of the forest of dislocations to the resistance of dislocation glide, $\mathrm{g}_{\mathrm{BH}}$, is calculated with a modified Bailey-Hirsch model, in which the leading coefficient $\alpha_{\mathrm{BH}}$ and the self and latent hardening coefficients in $\Omega^{(\mathrm{ma})}$ depend on the dislocation interactions in the particular metal being modeled. The third term in the slip resistance equation, gDBH, is the hardening due to precipitates, modeled here with a dispersed barrier hardening model. The dispersed barrier model requires the average precipitate diameter and the number density of the precipitates as inputs; this number density can be determined with the KJMA equation as described previously.

A continuum dislocation dynamics (CDD) based crystal plasticity model has already been implemented in Grizzly for the simulation of iron reactor pressure vessels. The goal of the initial crystal plasticity modeling efforts described here is to evaluate the suitability of this existing crystal plasticity model for aged $\mathrm{Ni}-\mathrm{Cr}$ alloy simulations. The CDD crystal plasticity model calculates the evolution of mobile and immobile dislocations densities separately, with a single mathematical terms per dislocation interaction mechanism [6]. 
Two simulation model geometries were used in this evaluation modeling effort: a single micropillar-only geometry with fixed displacement boundary conditions at the base and a micropillar on a substrate base geometry. In both the fixed base micropillar and the micropillarsubstrate geometries, a loading orientation in the [001] direction along the z-axis was used and a loading displacement rate of $2000 \mathrm{~nm} / 60 \mathrm{~s}$ was selected to match the experimental micropillar compression tests. In both geometries a pillar height of $14.95 \mu \mathrm{m}$ and a pillar width and depth of $5.0 \mu \mathrm{m}$ were used to match the micropillar compression experiment.

Elastic constants and material lattice parameters for Inconel 690 [7] were used. A Peierls-Nabarro stress on the order of $10^{-4}$ of the shear modulus was used, a value in line with other crystal plasticity simulations of $\mathrm{Ni}$ [8]. The precipitate number density and average precipitate diameter are taken from molecular dynamics simulations of long range ordered precipitate formation after 8,000 hours of ageing time [9].

Table 7. Material properties and parameters used in the crystal plasticity model

\begin{tabular}{ll}
\hline Property and Parameter Type & Value \\
\hline Elastic modulus $(\mathrm{E})$ & $209.53 \mathrm{GPa}$ \\
Shear modulus $(\mu)$ & $80.035 \mathrm{GPa}$ \\
Temperature $(\mathrm{T})$ & $298 \mathrm{~K} / 25^{\circ} \mathrm{C}$ \\
Burgers vector $(\mathrm{b})$ & $0.252 \mathrm{~nm}$ \\
Initial dislocation glide velocity $\left(\mathrm{vo}_{\mathrm{o}}\right)$ & $4.0 \mathrm{e}-5 \mathrm{~m} / \mathrm{s}$ \\
Strain rate sensitivity exponent $(\mathrm{m})$ & 0.012 \\
Initial dislocation density $\left(\rho_{\mathrm{o}}\right)$ & $9.0 \mathrm{e} 13 \mathrm{~m}^{-2}$ \\
& \\
Bailey-Hirsch model coefficient $(\alpha \mathrm{BH})$ & 0.4 \\
Self slip system hardening coefficient $\left(\Omega^{\alpha \alpha}\right)$ & 1.0 \\
Latent slip system hardening coefficient $\left(\Omega^{\alpha \beta}\right)$ & 1.0 \\
Dispersed barrier hardening coefficient $(\alpha \mathrm{DBH})$ & 0.06 \\
Precipitate number density, aged 8,000 hours $(\mathrm{N})$ & $3.65 \mathrm{e} 24 \mathrm{~m}^{-3}$ \\
Precipitate average diameter, aged 8,000 hours $(\mathrm{d})$ & $2.5 \mathrm{~nm}$ \\
\hline
\end{tabular}

Because of the reduced computational effort associated with the smaller geometry, the crystal plasticity parameter fitting was performed with the fixed base pillar-only geometry models. The values of the hardening mechanism parameters were fit to the yield stress data for $\mathrm{Ni}_{2} \mathrm{Cr}$ [5] for unaged $\mathrm{Ni}_{2} \mathrm{Cr}$ and $\mathrm{Ni}_{2} \mathrm{Cr}$ aged for 10,000 hours; the phase fraction of long range ordered precipitates was assumed to be stable between 8,000 hours and 10,000 hours. This assumption of stable precipitate number density is supported by the results of the KJMA equation, Figure 16. The values of the material properties, model parameters, and variable initial conditions resulting from the fitting are shown in in Table 7. Material properties and parameters used in the crystal plasticity model.

The value of the initial dislocation density, $\rho_{\mathrm{o}}$, required in the crystal plasticity simulations to match the experimentally reported yield stress is higher than values used in crystal plasticity simulations of other Ni-Cr alloys [7]; however, those simulations included the presence of alloying element precipitates while these simulations assume a perfect crystal lattice with only initial dislocations. The required higher initial dislocation density value is also an indication of the need 
for non-local or size-effect dependencies of the crystal plasticity model to capture the effect of grain size and small sample size on the simulation results. The addition of non-local terms in the Grizzly CDD crystal plasticity model will be the focus of future work. The value of the dispersed barrier hardening coefficient, $\alpha_{\mathrm{DBH}}$, is similar to values used for modeling the strengthening effect of irradiation defects on FCC metals in other crystal plasticity simulations.

The results of the simple fixed pillar geometry crystal plasticity simulations are shown in Figure 17 A mesh of 24 Hex8 elements was used in each simulation. A series of four different aging conditions was simulated with the Grizzly CDD crystal plasticity model, and the $0.2 \%$ offset strain yield stress values from the simulations are compared to the measured yield stress data from Young and Eno [5].
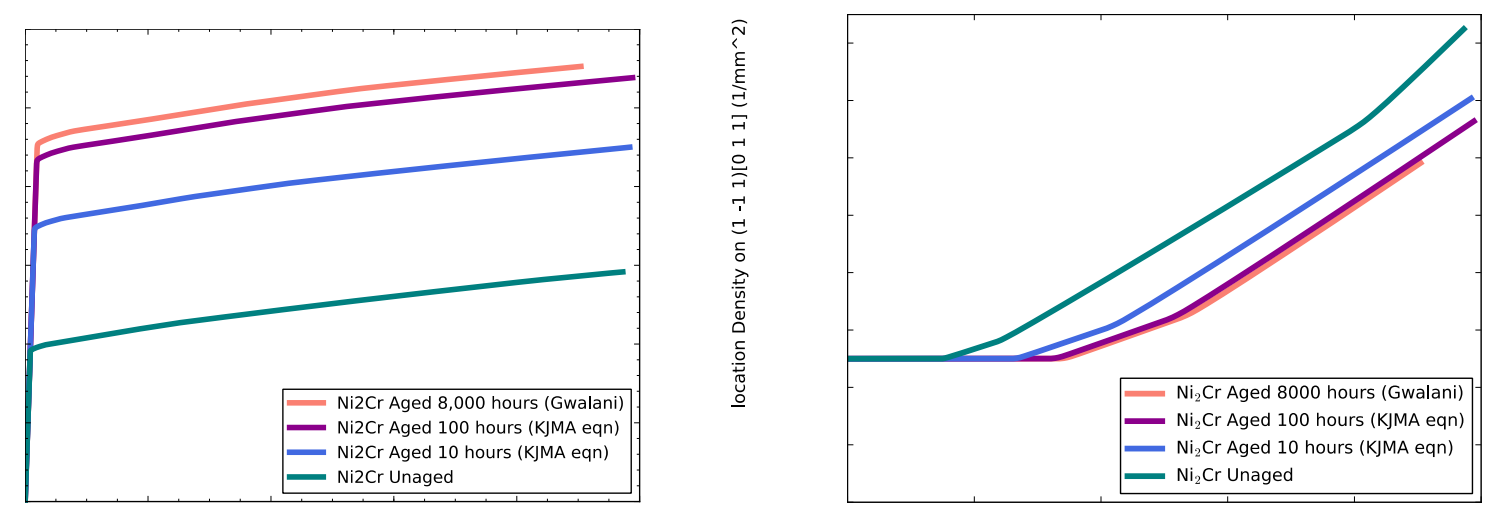

Figure 17. Von Mises Stress response (left) and active slip system (1 1 -1 1)[011] mobile dislocation density evolution (right) from crystal plasticity simulations of long range ordered precipitates from thermal ageing in a simplified fixed base pillar-only geometry loaded in the [001] direction.

The unaged and 8,000 hours conditioning simulations were used to fit the model hardening parameters, as discussed above. The simulations for 10 hours and 100 hours represent the initial benchmarking of the coupled KJMA equation and crystal plasticity model. The number density of precipitates at 8,000 hours [9] was considered to be the stable density value; the number densities of the lower condition time cases were determined by multiplying the result of the KJMA equation by the stable precipitate number density. The values of the precipitate densities and the resulting simulation yield stress are given in Table 8 . 
Table 8 . The Grizzly crystal plasticity precipitate number densities and the resulting yield stress predictions compared with experimentally measured yield stress values from [5]. The unaged and 8,000 hours aged cases were used to fit the crystal plasticity model hardening parameters, and the 10 hours and 100 hours cases were used to benchmark the coupled KJMA-crystal plasticity models.

\begin{tabular}{cccc}
\hline $\begin{array}{c}\text { Simulation } \\
\text { Conditioning Case }\end{array}$ & $\begin{array}{c}\text { Precipitate Number } \\
\text { Density }\left(\mathbf{m}^{-\mathbf{3}}\right)\end{array}$ & $\begin{array}{c}\text { Predicted Yield } \\
\text { Stress (MPa) }\end{array}$ & $\begin{array}{c}\text { Measured Yield } \\
\text { Stress (MPa) [5] }\end{array}$ \\
\hline Unaged & - & 200 & $200-250$ \\
10 hours & $1.28 \mathrm{e} 24$ & 360 & $290-300$ \\
100 hours & $3.11 \mathrm{e} 24$ & 440 & $425-440$ \\
8000 hours & $3.65 \mathrm{e} 24$ & 460 & $460-500$ \\
\hline
\end{tabular}

The initial benchmarking results for the 100 hours simulation fall within the upper bound of the experimentally measured yield stress while the 10 hours simulation result is above the corresponding measured value, see Table 8 . These preliminary results indicate the Grizzly crystal plasticity model is suitable for further modeling efforts.

One of the key modeling applications of interest for the crystal plasticity model is the micropillar compression test. TEM images of micropillar compression tests of nickel show a build up of dislocations at the base of the micropillar and the top of the substrate [10]. Previous simulation studies of micropillar-substrate geometries have shown that up to $20 \%$ of the deformation response measured in a micropillar compression experiment is due to the substrate [11].

A full 3D micropillar and substrate geometry, shown on the right in Figure 18, was used in a Grizzly crystal plasticity micropillar compression simulation. The build up of dislocations at the micropillar-substrate interface is reflected in the simulation dislocation evolution results while the simple fixed base pillar-only geometry demonstrates a higher dislocation density at the top of the pillar. Figure $3 \mathrm{X}$ shows the dislocation evolution at the onset of plasticity on one of the active slip systems: $\left(\begin{array}{lll}1 & -1 & 1\end{array}\right)\left[\begin{array}{lll}0 & 1 & 1\end{array}\right]$. The fixed base boundary conditions of the pillar-only geometry do not allow for the physical build up of dislocations at the pillar base under micropillar compression loading conditions. 


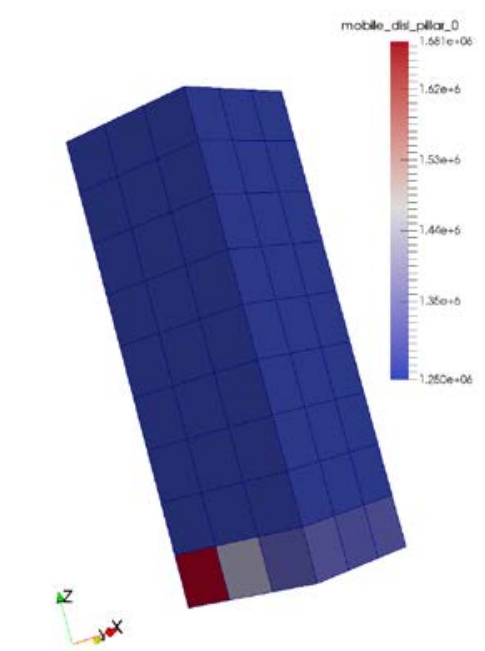

Micropillar-substrate geometry

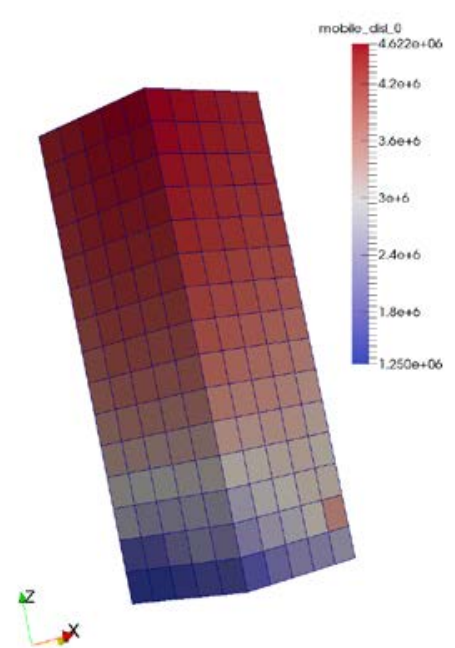

Fixed base pillar geometry

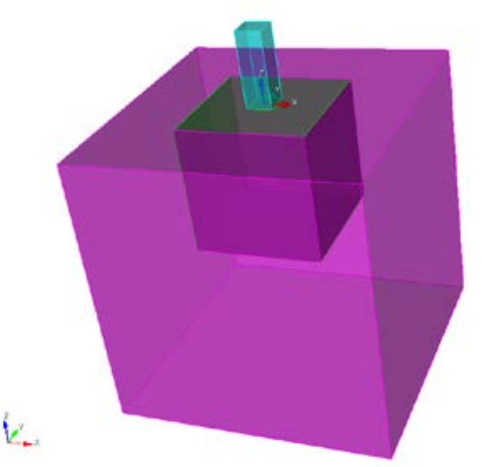

Figure 18. Comparison of the mobile dislocation evolution on the active (1 - 11 1)[011] slip system in the micropillar-substrate model and the simplified pillar-only model with fixed base geometry at the onset of plasticity (left). The complete 3D micropillar-substrate geometry is shown on the right; the blue and green regions are modeled with crystal plasticity while the pink region is modeled as an elastic isotropic material.

A natural consequence of the dislocation density build-up in the interface of the micropillar and substrate is a transmission of stress in the substrate. Understanding how the micropillar and the substrate individually contribute to the overall stress-strain response is necessary to correctly model the micropillar compression tests. Additional future work should include expanding the Grizzly crystal plasticity model to include dislocation-precipitate mechanisms for the ordered phase precipitates. An investigation of addition terms for precipitate-dislocation interaction, including anti-phase boundary particle shearing and dislocation pinning for additional Orowan looping should be conducted to better capture the effect of the long-range ordered precipitates on the dislocation behavior. 
Peer reviewed publications:

1) F. Teng, J.D. Tucker, Role of Stoichiometry on Ordering in Ni-Cr Alloys, MRS Online Proceedings Library Archive 1809 (2015).

2) Precipitation in an Irradiated 625 plus alloy, L-J Yu and EA Marquis, Microscopy \& Microanalysis 23 (Suppl 1) 2256 (2017).

3) F. Teng, L.-J. Yu, O. Ciuca, E. Marquis, G. Burke, J.D. Tucker, The Role of Stoichiometry on Ordering Phase Transformations in Ni-Cr Alloys for Nuclear Applications, Proceedings of the 18th International Conference on Environmental Degradation of Materials in Nuclear Power Systems-Water Reactors, Springer, Cham, (2018).

Student Theses:

1) "Role of Stoichiometry on Ordering in Ni-Cr Alloys." Fei Teng Master's of Science, Materials Science, Oregon State University, May 17, (2016).

Presentations:

1) "Role of Stoichiometry on Ordering in Ni-Cr Alloys", F. Teng, J.D. Tucker, MRS, San Francisco, CA, April 6 (2015).

2) "Role of Stoichiometry on Ordering in Ni-Cr Alloys", F. Teng, J.D. Tucker. TMS, Nashville, TN, February 16 (2016).

3) "Precipitation in an Irradiated 625 plus alloy", L-J Yu and EA Marquis, Microscopy \& Microanalysis, St Louis, MO, August (2016). [Poster] (awarded Best Poster Award)

4) "Thermal and irradiation-enhanced ordering in Ni-Cr alloys of varying stoichiometry", J.D. Tucker, F. Teng, E. Marquis, L.J. Yu, M. G. Burke, O. Ciuca and B. Spencer, The Nuclear Materials Conference (NuMat), Montpellier, France, November (2016).

5) "The Role of Stoichiometry on Ordering Phase Transformations in Ni-Cr Alloys for Nuclear Applications", F. Teng, B. Spencer, O. Ciuca, M.G. Burke, E. Marquis, M. Bachhav, L. Aagesen, P. Chakraborty, Y. Zhang, and J.D. Tucker, TMS Annual Meeting and Exhibition, San Diego, CA, March (2017).

6) "The Role of Stoichiometry on Ordering Phase Transformations in Ni-Cr Alloys for Nuclear Applications", F. Teng, L.-J. Yu, O. Ciuca, E. Marquis, G. Burke, J.D. Tucker, Proceedings of the 18th International Conference on Environmental Degradation of Materials in Nuclear Power Systems-Water Reactors, Portland, OR, August (2017). 


\section{REFERENCES}

1. Sandusky, D. and W. Lunceford, Assessment of Materials Issues for Light Water SMRs. 2013, Pacific Northwest National Laboratory.

2. Bajaj, R., et al. Effects of Neutron Irradiation on Mechanical Behavior of Ni-Base Fastener Alloys. in NACE. 2000.

3. Burke, M.G. and R. Bajaj, Radiation-Induced Precipitation in Direct-Aged Alloy 625, in Microscopy \& Microanalysis 96, G.W.B.e. al., Editor. 1996, San Francisco Press. p. 994-995.

4. Avrami, M., Granulation, phase change, and microstructure kinetics of phase change. III. The Journal of chemical physics, 1941.9(2): p. 177-184.

5. Young, G. and D. Eno, Long range ordering in model Ni-Cr-Xalloys. 2014.

6. Li, D., et al., Predicting plastic flow and irradiation hardening of iron single crystal with mechanismbased continuum dislocation dynamics. International Journal of Plasticity, 2014. 52: p. 3-17.

7. Blaizot, J., et al., Constitutive model for nickel alloy 690 (Inconel 690) at various strain rates and temperatures. International Journal of Plasticity, 2016. 80: p. 139-153.

8. Dimiduk, D., M. Uchic, and T. Parthasarathy, Size-affected single-slip behavior of pure nickel microcrystals. Acta Materialia, 2005. 53(15): p. 4065-4077.

9. Gwalani, B., et al., Experimental investigation of the ordering pathway in a Ni-33 at.\% Cralloy. Acta Materialia, 2016. 115: p. 372-384.

10. Frick, C., et al., Size effect on strength and strain hardening of small-scale [111] nickel compression pillars. Materials Science and Engineering: A, 2008. 489(1): p. 319-329.

11. Fei, H., et al., Evaluation of micro-pillar compression tests for accurate determination of elasticplastic constitutive relations. Journal of Applied Mechanics, 2012. 79(6): p. 061011. 


\section{APPENDIX A. IMR COMPOSITION CONFIRMATION REPORT}
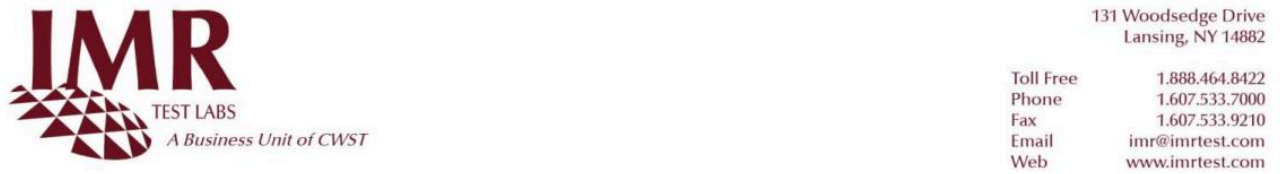

August 22, 2014

Julie Tucker

Oregon State University

204 Rodgers Hall

\section{TEST REPORT}

Corvallis, OR 97331

IMR Report Number 201410486

PONumber

P0096352

DateReceived

SUMMARY

August 15, 2014

Sample ID

$\mathrm{Ni} / \mathrm{Cr} 1.6$

$\mathrm{Ni} / \mathrm{Cr} 1.8$

$\mathrm{Ni} / \mathrm{Cr} 2.0$

$\mathrm{Ni} / \mathrm{Cr} 2.2$

$\mathrm{Ni} / \mathrm{Cr} 2.4$

Five samples were received for chemical analysis.

The results are on the following page(s).

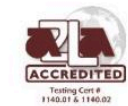

\section{Nadcap} informa sysem in compliance with the ISO/IEC 17025 and is accredited by the American Association for Laboratory Accreditation (A2LA), certificates $\# 1140.01$ and $\# 1140.02$ IMR Test Labs
quality systes will perform all testing in good faith using the proper procedures, trained personnel, and equipment to accomplish the testing required IMR's liability to the customer or any third party is himited at all tmes to the amount charged for the services provided. All samples will be retained for a minimum of 6 months and may be destroyed thereafter unless otherwise specified by the customer. The recording of alse, hictitious, or rraudulent statements or entres on this document may be punished as a felony under federal statu tes. IMR Test Labs is a GEAE S-40
approved lab (Supplier Code T3983).

Oregon State University

Page 1 of 2
Reviewed by

Andrew Ensign, Supervisor

Chemistry Department 


\section{CHEMISTRY}

\begin{tabular}{|c|c|c|c|c|c|}
\hline Element & $\mathrm{Ni} / \mathrm{Cr} \mathbf{1 . 6}$ & $\mathrm{Ni} / \mathrm{Cr} \mathbf{1 . 8}$ & $\mathrm{Ni} / \mathrm{Cr} \mathbf{2 . 0}$ & $\mathrm{Ni} / \mathrm{Cr} \mathbf{2 . 2}$ & $\mathrm{Ni} / \mathrm{Cr}$ 2.4 \\
\hline \hline $\mathrm{C}^{1}$ & 0.01 & 0.01 & 0.01 & 0.01 & 0.01 \\
\hline $\mathrm{Cr}$ & 31.17 & 32.95 & 30.62 & 28.58 & 27.36 \\
\hline $\mathrm{Fe}$ & $<0.01$ & $<0.01$ & $<0.01$ & $<0.01$ & 0.04 \\
\hline $\mathrm{P}$ & 0.006 & 0.007 & 0.006 & 0.006 & 0.006 \\
\hline $\mathrm{S}^{1}$ & 0.002 & 0.002 & 0.002 & 0.002 & 0.001 \\
\hline $\mathrm{Ni}^{2}$ & 68.81 & 67.03 & 69.36 & 71.40 & 72.58 \\
\hline
\end{tabular}

${ }^{1}$ Determined by combustion-infrared absorbance.

2Detrermined by difference.

Other elements tested (<0.01\%): Al, As, Au, B, Be, Bi, Ca, Cd, Ce, Co, Cu, Hf, $\mathrm{La}, \mathrm{Li}, \mathrm{Mg}, \mathrm{Mn}, \mathrm{Mo}, \mathrm{Nb}$,

$\mathrm{Pb}, \mathrm{Sb}, \mathrm{Se}, \mathrm{Si}, \mathrm{Sn}, \mathrm{Ta}, \mathrm{Ti}, \mathrm{V}, \mathrm{W}$, \& $\mathrm{Zr}$.

Results in weight percent unless otherwise indicated.

Method(s): CAP-017N (ICP-AES) and ASTM E 1019-11 (Comb./ IGF) 